\title{
Modelling bidirectional fluxes of methanol and acetaldehyde with the FORCAsT canopy exchange model
}

\author{
Kirsti Ashworth $^{1, \mathrm{a}}$, Serena H. Chung ${ }^{2}$, Karena A. McKinney ${ }^{3, \mathrm{~b}}$, Ying Liu ${ }^{3, \mathrm{~b}, \mathrm{c}}$, J. William Munger ${ }^{3,4}$, Scot T. Martin ${ }^{4}$, \\ and Allison L. Steiner ${ }^{1}$ \\ ${ }^{1}$ Climate and Space Science and Engineering, University of Michigan, Ann Arbor, MI 48109, USA \\ ${ }^{2}$ Department of Civil and Environmental Engineering, Washington State University, Pullman, WA 99164, USA \\ ${ }^{3}$ Department of Earth and Planetary Sciences, Harvard University, Cambridge, MA 02138, USA \\ ${ }^{4}$ School of Engineering and Applied Sciences, Harvard University, Cambridge, MA 02138, USA \\ ${ }^{a}$ now at: Royal Society Dorothy Hodgkin Research Fellow at Lancaster Environment Centre, Lancaster University, \\ LA1 4YQ, UK \\ ${ }^{\mathrm{b}}$ formerly at: of Department of Chemistry, Amherst College, Amherst, MA 01002, USA \\ ${ }^{\mathrm{c}}$ now at: Peking University, Beijing 100000, China
}

Correspondence to: Kirsti Ashworth (k.s.ashworth1@lancaster.ac.uk)

Received: 16 June 2016 - Published in Atmos. Chem. Phys. Discuss.: 30 June 2016

Revised: 27 November 2016 - Accepted: 28 November 2016 - Published: 15 December 2016

\begin{abstract}
The FORCAsT canopy exchange model was used to investigate the underlying mechanisms governing foliage emissions of methanol and acetaldehyde, two short chain oxygenated volatile organic compounds ubiquitous in the troposphere and known to have strong biogenic sources, at a northern mid-latitude forest site. The explicit representation of the vegetation canopy within the model allowed us to test the hypothesis that stomatal conductance regulates emissions of these compounds to an extent that its influence is observable at the ecosystem scale, a process not currently considered in regional- or global-scale atmospheric chemistry models.

We found that FORCAsT could only reproduce the magnitude and diurnal profiles of methanol and acetaldehyde fluxes measured at the top of the forest canopy at Harvard Forest if light-dependent emissions were introduced to the model. With the inclusion of such emissions, FORCAsT was able to successfully simulate the observed bidirectional exchange of methanol and acetaldehyde. Although we found evidence that stomatal conductance influences methanol fluxes and concentrations at scales beyond the leaf level, particularly at dawn and dusk, we were able to adequately capture ecosystem exchange without the addition of stomatal control to the standard parameterisations of foliage emissions, suggesting
\end{abstract}

that ecosystem fluxes can be well enough represented by the emissions models currently used.

\section{Introduction}

The exchange of many oxygenated volatile organic compounds (oVOCs) from forest canopies has recently been observed to be bidirectional, with periods of strongly positive (i.e. up out of the canopy to the atmosphere above) and negative (i.e. downward) fluxes (Park et al., 2013; Karl et al., 2005; McKinney et al., 2011). Several of these compounds, e.g. acetone, acetaldehyde, and methanol, are present in the atmosphere in large quantities (Singh et al., 1995; Heikes et al., 2002; Millet et al., 2010; Jacob et al., 2002). They are also chemically active, with acetone and acetaldehyde leading to the formation of PAN (peroxyacetyl nitrate) and the transport of reactive nitrogen to remote regions (Fischer et al., 2014), and methanol contributing significantly to the production of ground-level ozone (Tie et al., 2003). These oVOCs have potentially important implications for regional air quality and climate modelling and for estimating global atmospheric burdens of many trace gases (e.g. Folberth et al., 2006; Fischer et al., 2014). However, many regional and global atmospheric chemistry and transport models (CTMs) do not explicitly in- 
clude dynamic biogenic sources and sinks of oVOCs. While most now incorporate online calculations of biogenic emissions of isoprene and monoterpenes, based on the light and temperature-dependence algorithms developed by Guenther et al. (1995, 2006, 2012), methanol emissions have only been recently included in some CTMs (e.g. GEOS-Chem, Millet et al., 2010; Laboratoire de Météorologie Dynamique zoom (LMDz), Folberth et al., 2006), and most still rely on nondynamic emissions inventories for methanol and acetaldehyde if primary biogenic emissions of these species are included (e.g. UKCA; O'Connor et al., 2014). Furthermore, Ganzeveld et al. (2008) demonstrated the weaknesses of the algorithms currently used in 3-D chemistry transport models to calculate primary emissions of methanol online. Similarly, dry deposition schemes in CTMs are usually based on fixed deposition velocities (Wohlfahrt et al., 2015) or calculated from roughness lengths and leaf area index values assigned to generic land cover types (e.g. FRSGC-UCI, Wild et al., 2014; LMDz, Folberth et al., 2006). This simplistic approach to biogenic sources and sinks may be a critical omission limiting their capability of accurately simulating atmospheric composition in many world regions.

Here we focus on methanol and acetaldehyde, two oVOCs that are frequently observed in and above forests but whose sources, sinks, and net budgets are not known with any certainty (Seco et al., 2007; Niinemets et al., 2004). While biogenic sources of both are strongly seasonal, fluxes and concentrations can remain high throughout the growing season (Stavrakou et al., 2011; Millet et al., 2010; Hu et al., 2011; Karl et al., 2003; Wohlfahrt et al., 2015). Methanol fluxes are on the same order of magnitude as isoprene at many sites in the US (Fall and Benson, 1996), suggesting their regional and global importance. The fundamental mechanisms leading to the synthesis and/or subsequent release of methanol and acetaldehyde are not currently fully understood (Karl et al., 2002; Seco et al., 2007).

Methanol is known to be produced from demethylation processes during cell wall expansion and leaf growth with emissions peaking during springtime leaf growth and declining with leaf age (Fall and Benson, 1996). The factors controlling the subsequent release of methanol to the atmosphere are harder to decipher (Huve et al., 2007; Niinemets et al., 2004). Measurements at all scales, from leaf-level to branchenclosure and ground-based ecosystem-scale field measurements (e.g. Kesselmeier, 2001; Kesselmeier et al., 1997; Karl et al., 2003; Seco et al., 2015; Wohlfahrt et al., 2015), as well as satellite inversions (e.g. Stravakou et al., 2011) demonstrate a strong diurnal profile of methanol fluxes similar to that of isoprene (e.g. Fall and Benson, 1996). Methanol synthesis, unlike that of isoprene, is not specifically linked to photosynthesis and the light dependence observed in leaflevel emissions have been shown to result from regulation by the stomata due to the high solubility of methanol in water (e.g. Nemecek-Marshall et al., 1995; Niinemets and Reichstein, 2003a, b; Huve et al., 2007).
The pathways leading to both the synthesis and emission of acetaldehyde are not clear (Karl et al., 2002; Jardine et al., 2008). Acetaldehyde has long been known to be an oxidation product of ethanol produced in leaves under anoxic conditions (Kreuzwieser et al., 2000), but this cannot explain the strong emissions observed under normal environmental conditions in mid-latitude forests (e.g. Seco et al., 2007; Karl et al., 2003). Karl et al. (2003) observed that bursts of acetaldehyde were emitted during light-dark transitions and postulated that such emissions were associated with pyruvate decarboxylation. Leaf-level measurements of acetaldehyde emissions have also been found to be tightly coupled to stomatal aperture (e.g. Kreuzwieser et al., 2000; Karl et al., 2002; Niinemets et al., 2004), and it has been suggested that this may account for observed light-dependent ecosystemscale emissions of acetaldehyde (Jardine et al., 2008).

Previous studies have suggested that the role of stomatal conductance in determining net flux of oVOCs could be incorporated in large-scale models by adopting a compensation point approach (see e.g. Harley et al., 2007; Ganzeveld et al., 2008; Jardine et al., 2008). The compensation point for a given compound is the atmospheric concentration of that compound at which the leaf, plant, or canopy switches from acting as a net source to a net sink. While firmly based in plant physiology and plant response to environmental conditions, this approach would allow models lacking leaf-level processes to account for the changes in flux direction (Harley et al., 2007; Ganzeveld et al., 2008). Observational (Jardine et al., 2008) and modelling studies (Ganzeveld et al., 2008) have both shown the potential power of this approach, although Jardine et al. (2008) found that the compensation point was heavily dependent on light and temperature and may therefore not be straightforward to implement.

Here we use the FORCAsT (FORest Canopy-Atmosphere Transfer) canopy-atmosphere exchange model (Ashworth et al., 2015) to investigate the key processes driving fluxes of methanol and acetaldehyde, and we explore possible underlying causes of their bidirectional exchange. The model represents all within-canopy processes: primary emissions, chemical and photolysis reactions, turbulent mixing, and deposition. A particular strength of the FORCAsT model is the inclusion of plant processes relevant to photosynthesis and respiration; stomatal conductance is explicitly calculated by FORCAsT. We therefore focus on exploring the role of primary biogenic emissions of methanol and acetaldehyde on canopy-top fluxes. We assess the effectiveness of different representations of bVOC (biogenic volatile organic compound) emissions mechanisms in capturing ecosystem-scale fluxes. For the first time in a canopy exchange model, we implement a mechanism by which stomatal conductance explicitly regulates primary emissions in order to assess its role in governing primary emissions and influencing ecosystemscale bidirectional exchange of these key oVOCs. Using this mechanism, we compare modelled fluxes with those from traditional empirical algorithms for direct and storage emis- 
sions and with fluxes measured just above the top of the canopy at Harvard Forest in July 2012.

\section{Methods}

\subsection{Harvard Forest measurements}

Harvard Forest is situated in a rural area of Massachusetts, approximately $90 \mathrm{~km}$ from Boston and $130 \mathrm{~km}$ from Albany. It is classified as a mixed deciduous broadleaved forest, with red oak (36\%) and red maple (22\%) as the dominant species (Urbanski et al., 2007). Continuous measurements of micrometeorological variables and air pollutants have been made from the Environmental Monitoring Station (EMS) Tower, part of the AmeriFlux network, for 25 years (Urbanski et al., 2007; Munger and Wofsy, 1999a, b). The tower, located at $42.5^{\circ} \mathrm{N}$ and $72.2^{\circ} \mathrm{W}$ and an elevation of $340 \mathrm{~m}$, is $30 \mathrm{~m}$ high and is surrounded by primary forest with an average height of around $23 \mathrm{~m}$. The long-term meteorological measurements include photosynthetically active radiation (PAR), relative humidity $(\mathrm{RH})$, and air temperature at multiple heights on the tower, together with wind speed and direction recorded just below the top of the tower (at 29 m; Urbanski et al., 2007; Munger and Wofsy, 1999a). In addition to exchanges of $\mathrm{CO}_{2}$ collected to assess photosynthetic activity and productivity, concentrations of $\mathrm{CO}$ at the top of the tower and fluxes of $\mathrm{O}_{3}$ (at multiple heights on the tower) are also routinely measured (Munger and Wofsy, 1999c). $\mathrm{NO}$ and $\mathrm{NO}_{2}$ concentrations and fluxes have been recorded in the past (Munger et al., 1996, 1998), with the most recent measurements in 2002 (Horii et al., 2004). In addition to these continuous atmospheric measurements, a suite of other data are gathered periodically to determine ecosystem health and functioning. Such data include leaf area index, tree girth, litter mass, leaf chemistry, and soil moisture and respiration (Barford et al., 2001; Urbanski et al., 2007; Munger and Wofsy, 1999b).

Concentrations and fluxes of bVOCs and their oxidation products have also been measured at the EMS Tower during several summer growing seasons (McKinney et al., 2011; Goldstein et al., 1998, 1995), augmenting the AmeriFlux suite of observations. Between 7 June and 24 September 2012, a proton-transfer-reaction time-of-flight mass spectrometer (PTR-TOF-MS 8000, Ionicon Analytik $\mathrm{GmbH}$, Austria) was used to measure the concentrations of volatile organic compounds at the site. The PTR-TOF-MS is capable of rapidly detecting hundreds of different VOCs at concentrations as low as a few pptv. PTR-TOF-MS has been previously described by Jordan et al. (2009a, b) and Graus et al. (2010). The instrument utilises a high-resolution TOF detector (Tofwerk AG, Switzerland) to analyse the reagent and product ions and allows for exact identification of the ion molecular formula (mass resolution $>4000$ ).
Ambient air was sampled from an inlet mounted at the top of the $30 \mathrm{~m}$ EMS Tower at a total flow rate of $5 \mathrm{slpm}$ using a configuration identical to that used by McKinney et al. (2011) in 2007. $\mathrm{H}_{3} \mathrm{O}^{+}$reagent ions were used to selectively ionise organic molecules in the sample air. The instrument was operated with a drift tube temperature of $60^{\circ} \mathrm{C}$ and a drift tube pressure of 2.20 mbar. The drift tube voltage was set to $550 \mathrm{~V}$, resulting in an $E / N$ of $126 \mathrm{Td}$ ( $E$, electric field strength; $N$, number density of air in the drift tube; unit, Townsend, Td; $1 \mathrm{Td}=10^{-17} \mathrm{~V} \mathrm{~cm}^{2}$ ). PTR-TOF-MS spectra were collected at a time resolution of $5 \mathrm{~Hz}$. Mass calibration was performed every 2 min with data acquisition using the Tof-Daq v1.91 software (Tofwerk AG, Switzerland). A calibration system in which gas standards (Scott Specialty Gases) were added into a humidified zero air flow at controlled flow rates was used to establish the instrument sensitivities to VOCs. Every $3 \mathrm{~h}$ the inlet flow was switched to pass through a catalytic converter (platinum on glass wool heated to $350^{\circ} \mathrm{C}$ ) to remove VOCs and establish background intensities.

The PTR-TOF-MS captures the entire mass spectrum in each $5 \mathrm{~Hz}$ measurement, providing a continuous mixing ratio time series at each mass-to-charge ratio rather than the disjunct time series obtained in previous PTR-MS studies at this site (McKinney et al., 2011). As a result, direct, rather than virtual disjunct, eddy covariances were determined and are reported herein (Mueller et al., 2010). Wind speeds recorded at $8 \mathrm{~Hz}$ by a tridimensional sonic anemometer located at the same height and less than $1 \mathrm{~m}$ away from the gas inlet were averaged to a $5 \mathrm{~Hz}$ time base, synchronised with the mixing ratio data, and used in the eddy covariance calculations. Eddy covariance fluxes were calculated from the data for $30 \mathrm{~min}$ intervals using methods described in McKinney et al. (2011). Ambient mixing ratios were averaged over the same $30 \mathrm{~min}$ intervals for which fluxes were calculated. The $30 \mathrm{~min}$ average mixing ratios and fluxes were then binned by time of day to calculate diurnal averages.

Eddy covariance is a powerful technique for the direct detection and estimation of ecosystem-scale fluxes of trace gases within and above vegetation canopies (see reviews by Baldocchi, 2003, 2014). However, its reliability for measuring night-time fluxes can be low (Gu et al., 2005; Baldocchi, 2014; Goulden et al., 1996; Jarvis et al., 1997). Its successful application relies on assumptions of steady-state conditions, conditions that do not always exist at night (see e.g. Baldocchi, 2003). The night-time formation of a stable atmospheric layer near the surface can result in stratification, trapping trace gases below the instrument detection height and altering the footprint of the flux measurement ( $\mathrm{Gu}$ et al., 2005; Baldocchi, 2003), leading to high associated errors in flux estimation (Goulden et al., 1996). While we acknowledge that the magnitudes of the night-time fluxes recorded during summer 2012 may have large associated errors, we are confident that the direction of the exchange is well captured since the observed fluxes for different species were not 
Table 1. Atmospheric and meteorological measurements relevant to this study made between 7 June and 24 September 2012 at the EMS Tower in Harvard Forest.

\begin{tabular}{|c|c|c|c|}
\hline Type & Measurement & Height (m) & Instrument \\
\hline \multicolumn{4}{|l|}{ Chemical } \\
\hline Methanol, $\mathrm{CH}_{3} \mathrm{OH}^{\mathrm{a}}$ & Concentration, flux & 29 & PTR-TOF-MS, IconiconAnalytik \\
\hline Acetaldehyde, $\mathrm{CH}_{3} \mathrm{CHO}^{\mathrm{a}}$ & Concentration, flux & 29 & PTR-TOF-MS, IconiconAnalytik \\
\hline $\mathrm{CO}^{\mathrm{b}}$ & Concentration & 29 & $\begin{array}{l}\text { Modified IR-absorption gas-filter } \\
\text { correlation analyser }\end{array}$ \\
\hline $\mathrm{O}_{3}^{\mathrm{b}}$ & Concentration & $\begin{array}{l}29,24.1,18.3,12.7 \\
7.5,4.5,0.8,0.3\end{array}$ & UV absorbance instrument \\
\hline Water vapour ${ }^{\mathrm{c}}$ & Concentration & 29 & Licor $\mathrm{CO}_{2}-\mathrm{H}_{2} \mathrm{O}$ sensor \\
\hline \multicolumn{4}{|l|}{ Meteorological } \\
\hline Air temperature ${ }^{\mathrm{c}}$ & & $\begin{array}{l}29,27.9,22.6 \\
15.4,7.6,2.5\end{array}$ & $\begin{array}{l}30 \mathrm{~kW} \text { precision thermistor } \\
\text { in aspirated radiation shield }\end{array}$ \\
\hline $\mathrm{PAR}^{\mathrm{c}}$ & & $29,12.7$ & Quantum sensor \\
\hline Wind speed ${ }^{\mathrm{c}}$ & Horizontal, vertical & 29 & AT1 sonic anemometer \\
\hline Wind direction ${ }^{\mathrm{c}}$ & & 29 & AT1 sonic anemometer \\
\hline Relative humidity ${ }^{c}$ & & $\begin{array}{l}29,22.6,15.4 \\
7.6,2.5\end{array}$ & $\begin{array}{l}\text { Thin film capacitor sensor in } \\
\text { aspirated radiation shield }\end{array}$ \\
\hline
\end{tabular}

${ }^{a}$ Data provided by McKinney and Liu. ${ }^{\mathrm{b}}$ Munger and Wofsy (1999b). ${ }^{\mathrm{c}}$ Munger and Wofsy (1999a).

correlated, suggesting no systematic bias in the application of eddy covariance at this site.

Isoprene, total combined monoterpenes, MVK (methyl vinyl ketone) and MACR (methacrolein) (detected as a single combined species), methanol, acetaldehyde, and acetone were all detected at concentrations well above the PTR-MS detection limit and determined to be free from interference from other compounds (McKinney et al., 2011). Here we confine our analysis to concentrations and fluxes of methanol and acetaldehyde. Table 1 summarises the relevant flux, concentration, and meteorological measurements made at the EMS Tower during the summer of 2012.

\subsection{FORCAsT1.0 canopy exchange model}

FORCAsT (version 1.0) is a single column (1-D) model that simulates the exchange of trace gases and aerosols between the forest canopy and atmosphere. A full description of FORCAsT is given in Ashworth et al. (2015). Here we provide a brief overview, summarise biogenic emissions and flux calculations in the model and describe the simulations performed.

FORCAsT1.0 has 40 vertical levels of varying thickness extending to a height of $\sim 4 \mathrm{~km}$, with the highest resolution nearest the ground where the complexity is greatest, i.e. within the canopy space. Micrometeorological conditions (temperature, PAR, RH) within the canopy are determined prognostically by energy balance, accounting for the physical structure of the canopy. The gas-phase chemistry scheme incorporated in FORCAsT1.0 is a modified version of the CalTech Chemical Mechanism (CACM; Griffin et al., 2002,
2005; Chen and Griffin, 2005), which includes 300 species whose concentrations are solved at every chemistry timestep (currently $1 \mathrm{~min}$ ), plus $\mathrm{O}_{2}$ and water vapour (Ashworth et al., 2015). Of the species, 99 are assumed to be condensable, and are lumped into 11 surrogate groups based on similar volatility and structure. Aerosol-phase concentrations of these surrogate groups are also calculated at every timestep based on equilibrium partitioning (Ashworth et al., 2015; Chen and Griffin, 2005).

The CACM chemistry mechanism in FORCAsT treats methanol explicitly with no chemical sources (e.g., production from peroxy radicals) and a sink via oxidation by $\mathrm{OH}$ to produce formaldehyde. Acetaldehyde is not treated explicitly but is instead included in a lumped group of aldehydes (ALD1, with $<\mathrm{C}_{5}$ ). The oxidation reactions for this group are based on acetaldehyde and no other species is currently emitted into the ALD1 group. Acetaldehyde has a far greater number of chemical sources and sinks in the FORCAsT simulations of a forest environment than methanol. See Ashworth et al. (2015) for details of the reactions and reaction rates included in FORCAsT.

FORCAsT incorporates dry deposition of all species based on the resistance scheme of Wesely (1989) and modified by Gao et al. (1993). The scheme assumes that the rate of deposition of a compound to canopy surfaces is determined by atmospheric, boundary, and surface resistances operating in series or parallel analogous to electrical resistances. Atmospheric and surface boundary layer resistances are common to all chemical species and are dependent on turbulence. As FORCAsT includes an explicit representation of the canopy, 
Table 2. Boundary and initial conditions used for the FORCAsT simulations.

\begin{tabular}{|c|c|}
\hline Model parameter or variable & Value \\
\hline Total leaf area index $\left(\mathrm{m}^{2} \text { leaf area } \mathrm{m}^{-2} \text { ground area }\right)^{\mathrm{a}}$ & 3.67 \\
\hline Average canopy height $(\mathrm{m})^{\mathrm{b}}$ & 23.0 \\
\hline Average trunk height $(\mathrm{m})^{\mathrm{b}}$ & 6.0 \\
\hline \multicolumn{2}{|l|}{ Meteorology (values measured at $29 \mathrm{~m}$ ) } \\
\hline Air temperature $\left({ }^{\circ} \mathrm{C}\right)^{\mathrm{c}}$ & 20.9 \\
\hline Wind speed $\left(\mathrm{m} \mathrm{s}^{-1}\right)^{\mathrm{c}}$ & 1.589 \\
\hline Friction velocity, $u^{*}\left(\mathrm{~m} \mathrm{~s}^{-1}\right)^{\mathrm{d}}$ & 0.278 \\
\hline Standard deviation of vertical wind velocity, $\sigma_{\mathrm{w}}\left(\mathrm{m} \mathrm{s}^{-1}\right)^{\mathrm{d}}$ & 0.351 \\
\hline \multicolumn{2}{|l|}{ Concentrations at $29 \mathrm{~m}$ (ppbv) } \\
\hline Isoprene $\mathrm{e}^{\mathrm{e}}$ & 0.939 \\
\hline Total monoterpenes ${ }^{\mathrm{e}}$ & 0.449 \\
\hline MVK-MCR $\mathrm{e}^{\mathrm{I}}$ & 0.786 \\
\hline Methanol $^{\mathrm{e}}$ & 10.11 \\
\hline Acetaldehyde $\mathrm{e}^{\mathrm{H}}$ & 0.620 \\
\hline Acetone $\mathrm{e}^{\mathrm{e}}$ & 2.608 \\
\hline Ozone $^{f}$ & 33.54 \\
\hline $\mathrm{CO}^{\mathrm{f}}$ & 164.8 \\
\hline Water vapour ${ }^{\mathrm{c}}$ & $1.861 \%$ \\
\hline \multicolumn{2}{|l|}{ Miscellaneous } \\
\hline Ozone at ground level $(0.3 \mathrm{~m})^{\mathrm{f}}$ & $20.35 \mathrm{ppbv}$ \\
\hline Temperature at ground level $(2.5 \mathrm{~m})^{\mathrm{c}}$ & $18.1^{\circ} \mathrm{C}$ \\
\hline Soil temperature at $15,40,50$, and $90 \mathrm{~cm}$ depth $^{\mathrm{a}}$ & $\begin{array}{l}24.9,25.9,25.9 \\
21.4^{\circ} \mathrm{C}\end{array}$ \\
\hline Soil moisture at $15,40,50$, and $90 \mathrm{~cm} \mathrm{depth}^{\mathrm{a}}$ & $\begin{array}{l}0.18,0.15 \\
0.17,0.18\end{array}$ \\
\hline $\mathrm{NO}_{2}$ at $29 \mathrm{~m}^{\mathrm{g}}$ & $1.00 \mathrm{ppbv}$ \\
\hline $\mathrm{N}_{2} \mathrm{O}_{5}$ at $29 \mathrm{~m}^{\mathrm{g}}$ & $1.50 \mathrm{ppbv}$ \\
\hline
\end{tabular}

the surface resistance term includes cuticular, mesophyllic, and stomatal resistances, which are dependent on the physico-chemical properties of the depositing species as well as the light, temperature, and water potential of the leaf. The deposition scheme described in Ashworth et al. (2015) and Bryan et al. (2012) has been updated to include methanol. The deposition velocity of acetaldehyde is calculated using parameters for the lumped ALD1 group, and the parameters for ALD1 and methanol deposition are shown in Table 3.

While a 1-D model cannot capture horizontal transport, FORCAsT does include a simple parameterisation to account for advection (Bryan et al., 2012; Ashworth et al., 2015). For the simulations here, only advection of $\mathrm{NO}_{2}$ is considered, such that a $\mathrm{NO}_{2}$ mixing ratio of $1 \mathrm{ppbv}$ is set just above the canopy based on average midday (defined as 10:00-17:00 EST) $\mathrm{NO}_{x}$ and $\mathrm{NO}_{y}$ (total reactive nitrogen species) concentrations. While nitrogen species were not measured at Harvard Forest in 2012, concentrations reported from the site by Munger et al. (1996) are extrapolated to 2012 using July monthly average $\mathrm{NO}_{x}$ levels measured at the nearby US EPA monitoring station at Ware $42.3^{\circ} \mathrm{N}, 72.3^{\circ} \mathrm{W}$, elevation $312 \mathrm{~m}$ (roughly $30 \mathrm{~km}$ southwest of the EMS Tower). This scaling accounts for the observed decrease in $\mathrm{NO}_{x}$ levels across the region as a result of emission reduction strategies (see e.g. EPA, 2015). All $\mathrm{NO}_{x}$ is assumed to be advected as $\mathrm{NO}_{2}$. The initial concentration of $\mathrm{N}_{2} \mathrm{O}_{5}$ at $29 \mathrm{~m}$ was set to give an average $\mathrm{NO}_{x}: \mathrm{NO}_{y}$ ratio of 0.4 (Munger et al., 1996), assuming all residual $\mathrm{NO}_{y}$ to be $\mathrm{N}_{2} \mathrm{O}_{5}$ initially. Lee et al. (2006) also reported that air masses reaching the Harvard Forest site from the north, northwest, and west had consistently low levels of anthropogenic VOCs. Such conditions prevailed $>60 \%$ of July 2012, and we found that including advection as an additional source of methanol and acetaldehyde did not improve model fit (results not shown). 
Table 3. Deposition parameters for methanol and acetaldehyde.

\begin{tabular}{|c|c|c|c|}
\hline Chemical & Henry's law constant & Diffusivity & Reactivity factor \\
\hline Methanol & $2.2 \mathrm{E} 02^{\mathrm{a}}$ & $1.33^{\mathrm{b}}$ & $1.0^{\mathrm{c}}$ \\
\hline ALD1 (acetaldehyde) ${ }^{\mathrm{d}}$ & 11.4 & 1.6 & 1.0 \\
\hline
\end{tabular}

${ }^{a}$ Sander (1999). ${ }^{b}$ Wesely (1989). ${ }^{c}$ Karl et al. (2010). ${ }^{d}$ Ashworth et al. (2015).

\subsubsection{Flux calculations}

Fluxes of gases and particles are calculated to be proportional to both the concentration gradient and the efficiency of vertical mixing between adjacent model layers (Eq. 1). Upward fluxes are modelled as positive and occur when the concentration of a particular species is higher at a lower height. The flux, $F_{i}\left(\mathrm{~kg} \mathrm{~m}^{-2} \mathrm{~s}^{-1}\right)$ of an individual species, $i$, between two model levels is given by

$F_{i}=-K_{H} \frac{\Delta C_{i}}{\Delta z}$

where $K_{H}$ is the eddy diffusivity $\left(\mathrm{m}^{2} \mathrm{~s}^{-1}\right), \Delta C_{i}$ the difference in mass concentrations $\left(\mathrm{kg}^{-1}\right)$ at the mid-height of the levels, and $\Delta z$ the difference in height $(\mathrm{m})$ between the levels. Eddy diffusivity, concentrations of all gas-phase and aerosol species, and fluxes are calculated at 1 min timesteps. The eddy diffusivity at the instrument height of $29 \mathrm{~m}$ is constrained by observed wind speeds (Bryan et al., 2012).

Vertical mixing is calculated prognostically in the model following Blackadar (1979) and is driven by observed top-ofcanopy radiation and wind speed. The within-canopy wind profile is calculated following Baldocchi (1988). Turbulence and mixing in the canopy space is then modified according to Stroud et al. (2005), with wind speed and eddy diffusivity constrained to observations at the top of the canopy. A full description of the vertical mixing and its impact on concentration gradients is described in Bryan et al. (2012).

Modelled fluxes should be viewed as an instantaneous snapshot, both temporally and spatially, as the calculation relies heavily on the concentration gradient across an arbitrary boundary level, in this case the instrument height of $29 \mathrm{~m}$. Actual concentration gradients display rapid fluctuations (see e.g. Steiner et al., 2011) due to heterogeneity in emissions (see e.g. Bryan et al., 2015) and chemistry (see e.g. Butler et al., 2008), as well as the occurrence of coherent structures that can result in counter-gradient flow of matter (Steiner et al., 2011 and references therein).

\subsubsection{Biogenic emissions}

Emissions of VOCs from vegetation can be described as following one of two possible routes (Grote and Niinemets, 2008). In the first, the compound is released to the atmosphere immediately on production (e.g. isoprene). Such emissions are tightly coupled to photosynthesis and are there- fore dependent on both temperature and light, falling to zero at night. We refer to such emissions as "direct". In the second pathway, VOCs are stored in specialist structures within the plant after their production (e.g. monoterpenes). Emissions from these storage pools occur by diffusion and are controlled by temperature alone. We term these "storage" emissions. It is thought that emissions of oVOCs are a combination of these ("combo"), with a proportion released directly on synthesis and the remaining fraction emitted from storage pools.

Emission rates are calculated in FORCAsT by modifying basal emission factors (rates at standard conditions, usually $30^{\circ} \mathrm{C}$ and $1000 \mu \mathrm{mol} \mathrm{m}{ }^{-2} \mathrm{~s}^{-1}$ of PAR) according to empirical relationships describing their dependence on light and temperature. These modifications (referred to as activity factors) follow the standard parameterisations of Guenther et al. (1995, 2012). For storage emissions, which are modelled as dependent on temperature only, the activity factor is a simple exponential relationship:

$\gamma_{T}=e^{-\beta\left(T_{\mathrm{L}}-T_{\mathrm{S}}\right)}$,

where $\gamma_{T}$ is the temperature-dependent activity factor for storage emissions, $\beta$ the temperature response factor $\left(\mathrm{K}^{-1}\right)$, $T_{\mathrm{S}}$ is $293 \mathrm{~K}$, and $T_{\mathrm{L}}(\mathrm{K})$ the leaf temperature (see Guenther et al., 2012). For further details of the activity factors for direct emissions included in FORCAsT the reader is referred to Ashworth et al. (2015) and references therein.

\subsection{Stomatal resistance}

FORCAsT includes a physical representation of a forest canopy, with the lowest eight model levels set as trunk space and the next 10 as crown space. The 10 crown space levels contain the foliage; the total leaf area estimated for 2012 based on litter fall is distributed among the levels according to balloon measurements made at the site by Parker (1999). Within each crown space level, the leaves are assigned to one of nine equally spaced angle classes assuming a spherical canopy based on leaf normal angle (Goel and Strebel, 1984) and the fraction of shaded leaf area calculated. Photosynthetic parameters, including stomatal resistance, are then calculated for each leaf angle class at each level within the crown space. The stomatal conductance (inverse of stomatal resistance) describes the aperture of the stomata and determines evapotranspiration (hence heat flux and energy bal- 
ance) and deposition rates within FORCAsT. It is not currently used to control the rate of biogenic emissions.

Stomatal resistance is modelled according to leaf temperature, PAR, water potential, and vapour pressure deficit using the relationships developed by Jarvis (1976) as described by Baldocchi et al. (1987). The overall stomatal resistance $\left(r_{\mathrm{s}}\right)$ is the product of these individual factors (Eq. 3), which are summarised below in Eqs. (4)-(8).

$r_{\mathrm{s}}=r_{\mathrm{smin}} \cdot r_{\mathrm{s}}(\mathrm{PAR}) \cdot r_{\mathrm{s}}(T) \cdot r_{\mathrm{s}}(D) \cdot r_{\mathrm{s}}(p)$,

where $r_{\mathrm{S}}(\mathrm{PAR})$ is the response of stomatal resistance to changes in PAR, $r_{\mathrm{smin}}\left(\mathrm{s} \mathrm{m}^{-1}\right)$ is the minimum stomatal resistance, and $b_{\mathrm{rs}}$ is an empirical coefficient.

$r_{\mathrm{S}}(\mathrm{PAR})=r_{\mathrm{smin}}\left(1+\frac{b_{\mathrm{rs}}}{\mathrm{PAR}}\right)$

$r_{S}(T)$ is the response of stomatal resistance to changes in leaf temperature $\left(T_{\mathrm{lf}} ;{ }^{\circ} \mathrm{C}\right), T_{\min }, T_{\max }$, and $T_{0}$ are the minimum and maximum temperatures for stomatal opening and optimum temperature respectively:

$$
\begin{aligned}
r_{\mathrm{s}}(T) & =\left\{\left(\frac{T_{\mathrm{lf}}-T_{\min }}{T_{0}-T_{\min }}\right)\left(\frac{T_{\max }-T_{\mathrm{lf}}}{T_{\max }-T_{0}}\right)^{b_{\mathrm{T}}}\right\}^{-1}, \\
b_{T} & =\left(\frac{T_{\max }-T_{0}}{T_{\max }-T_{\min }}\right) .
\end{aligned}
$$

$r_{\mathrm{S}}(d)$ is the relationship between stomatal resistance and vapour pressure deficit ( $D$; mbar), and $b_{\mathrm{v}}$ is an empirical coefficient:

$r_{\mathrm{s}}(D)=\left(1+\frac{b_{v}}{D}\right)^{-1}$

Water potential is assumed to act only once a threshold value is reached. Above this value it is modelled as

$r_{\mathrm{s}}(\varphi)=\left(\frac{1}{a \cdot \varphi+b_{w}}\right)$,

where $\varphi$ is the water potential (bar) and $a$ and $b_{w}$ are constants. Below the water potential threshold, $r_{\mathrm{S}}(\varphi)$ is taken as unity. The values of the constants used in these calculations are shown in Table 4.

Stomatal resistance is only calculated in FORCAsT during the day (defined within FORCAsT as PAR $\geq 0.01 \mathrm{~W} \mathrm{~m}^{-2}$ ); at night stomatal resistance is assumed equal to the minimum cuticular resistance $\left(3000 \mathrm{~s} \mathrm{~m}^{-1}\right)$.

\subsection{FORCAsT simulations}

All model simulations were performed for an average day in July 2012, the middle of the growing season, to ensure that measurement data did not include either the spring burst of methanol or elevated acetaldehyde emissions during senescence. FORCAsT was initiated with site-specific parameters
Table 4. Values of stomatal resistance coefficients and parameters used in FORCAsT.

\begin{tabular}{lr}
\hline Coefficient & Value \\
\hline$r_{\text {smin }}$ & 90.0 \\
$b_{\mathrm{rs}}$ & 200.0 \\
$T_{\min }$ & -2.0 \\
$T_{\max }$ & 45.0 \\
$T_{0}$ & 30.0 \\
$b_{v}$ & 0.5 \\
$a$ & 0.066667 \\
$b_{\varphi}$ & 1.6666667 \\
\hline
\end{tabular}

and measurements of the physical structure of the canopy and environmental conditions (Table 2). Initial meteorological conditions and atmospheric concentrations of chemical species were taken from the 2012 EMS Tower data (see Table 2). Initial air temperature above the canopy is calculated online using the average lapse rate observed by the radiosonde at Albany (the nearest sounding station, $\sim 90 \mathrm{~km}$ from Harvard Forest) and within the canopy by interpolation with the $2 \mathrm{~m}$ temperature reading. Concentrations of $\mathrm{O}_{3}$ within the canopy are based on observations from the EMS Tower, and concentrations above the canopy follow a typical night-time profile as described in Forkel et al. (2006). Concentrations of other species are assumed to decay exponentially with height such that the $e$-folding height is $100 \mathrm{~m}$ for short-lived species and $1000 \mathrm{~m}$ for longer-lived compounds. All model simulations started at 00:00 EST and continued for $48 \mathrm{~h}$, with the same driving data used for each $24 \mathrm{~h}$ period and analysis confined to the second day to account for model spin-up.

In addition to a baseline simulation, we perform a series of simulations that represent the potential bVOC emissions routes using the "traditional" algorithms based on the observed light and/or temperature dependence encapsulated in the MEGANv2.1 model of Guenther et al. (2012); see Sect. 2.2.2. We then introduce stomatal control to the temperature-only-dependent emissions (i.e. those from storage pools) to determine whether the observed leaf-level regulation of the emissions of oVOCs by stomatal aperture affects ecosystem-scale fluxes (Sect. 2.3.3). A final series of sensitivity tests explores the extent to which stomatal control governs canopy-top fluxes (Sect. 2.3.3). Table 5 summarises the simulations and sensitivity tests.

Model performance was evaluated against average fluxes and concentrations measured at $29 \mathrm{~m}$ throughout July 2012 at Harvard Forest. The raw measurement data were grouped and averaged for each model output time for the duration of the campaign period to create "typical" diurnal profiles of methanol and acetaldehyde fluxes and concentrations. The flux data in particular exhibited large variability, introducing high uncertainty to the assessment. Observations of both fluxes and concentrations of acetaldehyde were more vari- 
Table 5. Modifications to the base case for each of the sensitivity simulations.

\begin{tabular}{|c|c|}
\hline Simulation & Changes from baseline simulation \\
\hline \multicolumn{2}{|c|}{ Emissions $(E)$ of methanol and acetaldehyde included: } \\
\hline$E$-direct & $100 \%$ direct emissions \\
\hline$E$-storage & $100 \%$ storage emissions \\
\hline$E$-combo & 80 direct, $20 \%$ storage \\
\hline$E$-combo90 & 90 direct, $10 \%$ storage \\
\hline \multicolumn{2}{|c|}{ Stomatal control ( $S$ ) of storage emissions included: } \\
\hline$S$-storage & $\begin{array}{l}\text { Activity factor, } \gamma_{T} \text {, for storage emissions scaled by stomatal control factor, } \\
R_{\text {fct }} \text { (Eqs. } 2 \text { and } 9 \text {, with } n=3 \text { ) }\end{array}$ \\
\hline$S$-combo & $\begin{array}{l}\text { Activity factor, } \gamma_{T} \text {, for storage emissions scaled by stomatal control factor, } \\
R_{\text {fct }} \text { (Eqs. } 9 \text { and } 10 \text {, with } n=3 \text { ); } 80 \text { direct and } 20 \% \text { storage }\end{array}$ \\
\hline \multicolumn{2}{|c|}{ Stomatal control of storage emissions using modified stomatal control factor, $R_{\mathrm{fct}}(\mathrm{R})$ : } \\
\hline$R$-storage & Threshold stomatal control factor used (Eq. 11) \\
\hline$R$ storageP & $\begin{array}{l}\text { Threshold stomatal control factor used (Eq. 11) and daytime threshold } \\
\text { for PAR increased to } 10.0\end{array}$ \\
\hline$R$-storageN15 & $\begin{array}{l}\text { Threshold stomatal control factor used (Eq. 11) with scaling } \\
\text { factor } n \text { set to } 1.5\end{array}$ \\
\hline$R$-storageN6 & $\begin{array}{l}\text { Threshold stomatal control factor used (Eq. 11) with scaling } \\
\text { factor } n \text { set to } 6.0\end{array}$ \\
\hline$R$-combo & $\begin{array}{l}\text { Threshold stomatal control factor used (Eq. 11); } 80 \text { direct } \\
\text { and } 20 \% \text { storage }\end{array}$ \\
\hline$R$-comboP & $\begin{array}{l}\text { Threshold stomatal control factor used (Eq. 11) and daytime threshold for } \\
\text { PAR increased to } 10.0 ; 80 \text { direct and } 20 \% \text { storage }\end{array}$ \\
\hline$R$-comboN15 & $\begin{array}{l}\text { Threshold stomatal control factor used (Eq. 11) with scaling factor } n \text { set } \\
\text { to } 1.5 ; 80 \text { direct and } 20 \% \text { storage }\end{array}$ \\
\hline$R$-comboN6 & $\begin{array}{l}\text { Threshold stomatal control factor used (Eq. 11) with scaling factor } \\
n \text { set to } 6.0 ; 80 \text { direct and } 20 \% \text { storage }\end{array}$ \\
\hline
\end{tabular}

able than those of methanol, reflecting the greater number of chemical sources and sinks of acetaldehyde in conjunction with lower emission rates. The observations referred to throughout the main text and shown in Figs. 4, 6, and 7 are these averages of the campaign data.

\subsubsection{Baseline}

All simulations were driven using meteorology for an average July day with initial conditions set to July average values for all variables at 00:00 EST (shown in Table 2). For the baseline simulation, default FORCAsT settings for emissions, dry deposition and chemical production and loss (Ashworth et al., 2015) were used; the default FORCAsT settings do not consider primary emissions of methanol and acetaldehyde. Only primary emissions of isoprene and the monoterpenes $\alpha$-pinene, $\beta$-pinene, and $d$-limonene are included in the base case, with emission factors (Table 6a) based on average rates for mixed deciduous woodland in North America (Geron et al., 2000; Helmig et al., 1999).

\subsubsection{Primary emissions sensitivity tests}

Simulations including primary emissions of methanol and acetaldehyde were conducted to understand the effect of adding primary emissions of oVOCs. The specific changes from the baseline are described below and summarised in Table 5 .

In the first three "emissions" (E-) simulations, primary emissions of methanol and acetaldehyde are included: firstly with all emissions assumed to be direct ( $E$-direct), then all from storage pools ( $E$-storage), and finally as a combination of the two, with $80 \%$ taken to be direct and the remainder storage ( $E$-combo). Emission rates for methanol and acetaldehyde (Table 5) were initially based on standard emission factors for methanol and bidirectional VOCs respectively for temperate deciduous broadleaved trees given by Guenther et al. (2012) and scaled for this site by isoprene emission factor. The emission factors were then modified to best reconcile modelled and observed concentrations and fluxes at $29 \mathrm{~m}$ whilst conserving the total canopy emissions for each species as far as possible. For each simulation, $24 \mathrm{~h}$ aggregate emissions were within $\sim 10 \%$ of each other. The proportion of 80 direct and $20 \%$ storage emissions in- 
Table 6. (a) Emission factors (nmol m${ }^{-2}$ (projected leaf area) $\mathrm{s}^{-1}$ ) for VOCs included in FORCAsT baseline simulation. (b) Emission factors, $\varepsilon$ (nmol m ${ }^{-2}$ (projected leaf area) $\mathrm{s}^{-1}$ ) and total canopy emissions $\left(\mathrm{mg} \mathrm{m}^{-2}\right.$ day $^{-1}$ ) for methanol and acetaldehyde for the FORCAsT simulations in Table 5.

\begin{tabular}{lrrr|rrr}
\hline (a) VOC & Direct & Storage & & & \\
\hline Isoprene & $4.83^{\mathrm{a}}$ & 0.000 & & & \\
$\alpha$-pinene & 0.000 & $0.071^{\mathrm{b}}$ & & & \\
$\beta$-pinene & 0.000 & $0.032^{\mathrm{b}}$ & & & \\
$d$-limonene & 0.000 & $0.054^{\mathrm{b}}$ & & & \\
Methanol & 0.000 & 0.000 & & & \\
Acetaldehyde & 0.000 & 0.000 & & & \\
\hline (b) oVOC & \multicolumn{7}{c}{ Methanol } & & & \\
\hline Simulation & Direct $\varepsilon$ & Storage $\varepsilon$ & Total & Direct $\varepsilon$ & Storage $\varepsilon$ & Total \\
\hline$E$-direct & 4.894 & 0.000 & 435.8 & 0.303 & 0.000 & 28.7 \\
$E$-storage & 0.000 & 0.653 & 457.0 & 0.000 & 0.036 & 28.5 \\
$E$-combo & 1.670 & 0.418 & 441.2 & 0.112 & 0.027 & 32.0 \\
$E$-combo90 & 2.815 & 0.296 & 457.8 & 0.175 & 0.019 & 31.6 \\
$S$-storage & 0.000 & 0.326 & 441.0 & 0.000 & 0.019 & 32.1 \\
$S$-combo & 1.065 & 0.266 & 454.7 & 0.063 & 0.015 & 31.3 \\
$R$-storage & 0.000 & 0.653 & 438.6 & 0.000 & 0.040 & 30.5 \\
$R$-storageN15 & 0.000 & 0.653 & 429.5 & 0.000 & 0.040 & 31.2 \\
$R$-storageN6 & 0.000 & 0.751 & 445.6 & 0.000 & 0.046 & 30.9 \\
$R$-combo & 1.670 & 0.418 & 434.0 & 0.112 & 0.027 & 31.5 \\
$R$-comboN15 & 1.670 & 0.418 & 435.8 & 0.112 & 0.027 & 28.7 \\
$R$-comboN6 & 1.670 & 0.418 & 457.0 & 0.112 & 0.027 & 28.5 \\
$S$-storageP & 0.000 & 0.326 & 441.2 & 0.000 & 0.019 & 32.0 \\
$S$-comboP & 1.065 & 0.266 & 457.8 & 0.063 & 0.015 & 31.6 \\
$R$-storageP & 0.000 & 0.653 & 441.0 & 0.000 & 0.040 & 32.1 \\
$R$-comboP & 1.670 & 0.418 & 454.7 & 0.112 & 0.027 & 31.3 \\
\hline & & & & & \\
\hline
\end{tabular}

a Helmig et al. (1999). ${ }^{\mathrm{b}}$ Geron et al. (2000).

cluded in $E$-combo simulations was also based on the "lightdependent fractions" assigned to methanol and bidirectional VOCs by Guenther et al. (2012). A sensitivity test with the combination of 90 direct and $10 \%$ storage ( $E$-combo 90$)$ was also performed. For each simulation, emission factors and total emissions are listed in Table $6 \mathrm{~b}$, and diel profiles of total emissions, deposition, and canopy chemical production and loss are shown in Fig. 1. While the general pattern of emissions is the same in all simulations (Fig. 1a, b), the magnitude of the midday peak and overnight emission rate vary between the different emission pathways introduced. The greater the contribution from storage, the higher the overnight fluxes and the smaller the diurnal amplitude with $E$-direct (green line, $0 \%$ storage emissions) and $E$-storage (blue line, $100 \%$ storage) representing the extreme cases. Changes in emission rates alter the concentrations of methanol or acetaldehyde within the crown space, driving differences in both dry deposition (Fig. 1c, d) and chemical production and loss (Fig. 1e, f) rates. Figure 1 further demonstrates the relatively small contribution of chemical production and loss to the canopy space budgets of methanol and acetaldehyde.

\subsubsection{Stomatal control sensitivity tests}

Previous theoretical and laboratory-based studies have demonstrated the importance of stomatal aperture in the regulation of emissions of oVOCs from storage structures (e.g. Niinemets and Reichstein, 2003a, b; Nemecek-Marshall et al., 1995; Huve et al., 2007; Karl et al., 2002). Controlled experiments and leaf-level measurements suggest that emissions of many VOCs are dependent on stomatal conductance, although the extent to which the stomata regulate emission rates is highly dependent on both the compound and the leaf structure (Niinemets and Reichstein, 2003a).

Further sensitivity tests were performed specifically to test the dependence of the emissions of methanol and acetaldehyde on stomatal conductance. Stomatal resistance (the reciprocal of conductance) is explicitly calculated for every canopy level at every model time step based on incident PAR, leaf temperature and water potential (Eq. 3). In this series of tests, the calculated resistances were used to scale the temperature dependence of storage emissions of methanol and acetaldehyde (given in Eq. 2) for both the storage and combo 

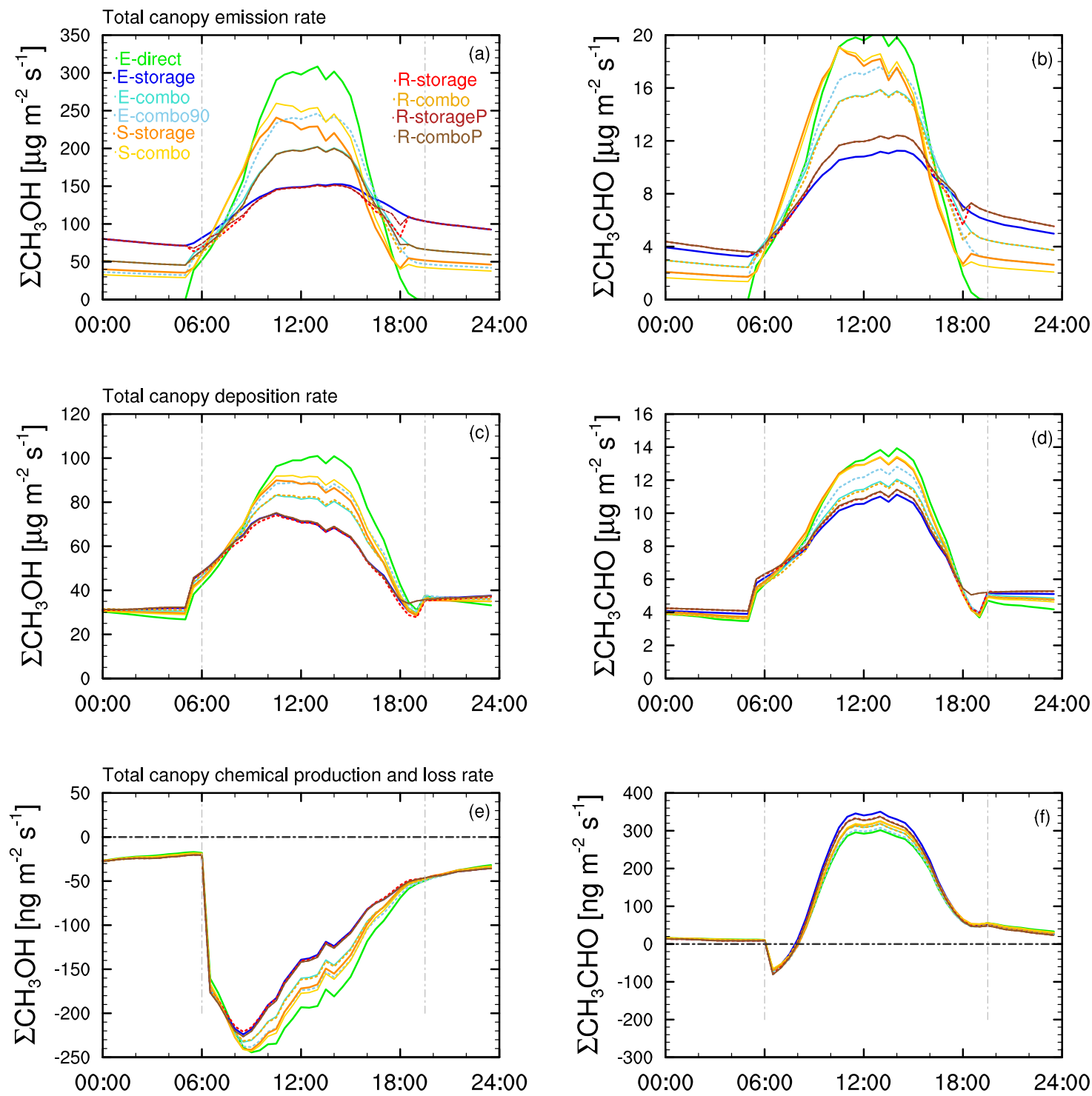

Figure 1. Total canopy production and loss rates per unit ground area for methanol (left) and acetaldehyde (right) summed over the 10 crown space layers. Coloured lines show total emissions (top), deposition (middle), and chemical production and loss (bottom) for each simulation.

emission pathways as shown in Eq. (9).

$\gamma_{\mathrm{TR}}=\gamma_{\mathrm{T}} \cdot R_{\mathrm{fct}}=e^{-\beta\left(T_{\mathrm{L}}-T_{\mathrm{S}}\right)} \cdot R_{\mathrm{fct}}$,

where $R_{\mathrm{fct}}$ is a stomatal control factor.

In the first of the "stomatal control" $(S$ - $)$ sensitivity tests, $R_{\mathrm{fct}}$ increased proportionally with stomatal conductance (i.e. inversely with stomatal resistance) as shown in Eq. (10):

$R_{\mathrm{fct}}=\frac{3000}{n \cdot R_{\mathrm{stom}}}$

where $R_{\text {stom }}\left(\left(\mu \mathrm{mol} \mathrm{m}{ }^{-2} \mathrm{~s}^{-1}\right)^{-1}\right)$ is the stomatal resistance, $3000\left(\mathrm{~s} \mathrm{~m}^{-1}\right)$ is the model default limiting night-time value of $R_{\text {stom }}$ and $n$ is a scaling factor. The night-time "stomatal" resistance is in fact equal to the cuticular resistance and $n$ was introduced to account for this. (During the day, the leaf resistance, the combination of the stomatal and cuticular resistances in parallel, is dominated by the stomatal resistance). The value of $n$ was initially set to 3 for the $S$-storage and $S$ combo simulations, as Jarvis (1976) reported a limiting value of 1000, although this was species dependent. The effect of the choice of value of $n$ is explored in Sect. 3.5.

Figure 2 shows the diel cycle of stomatal resistances calculated in FORCAsT for each model level within the crown space; an average canopy resistance is also indicated. $R_{\text {stom }}$ is set to 3000 overnight and falls to a minimum during the middle of the day when light levels are highest in the canopy. $R_{\text {stom }}$ is lower at the top of the canopy and increases with increasing depth into the foliage layers. The profile of $R_{\mathrm{fct}}$ 

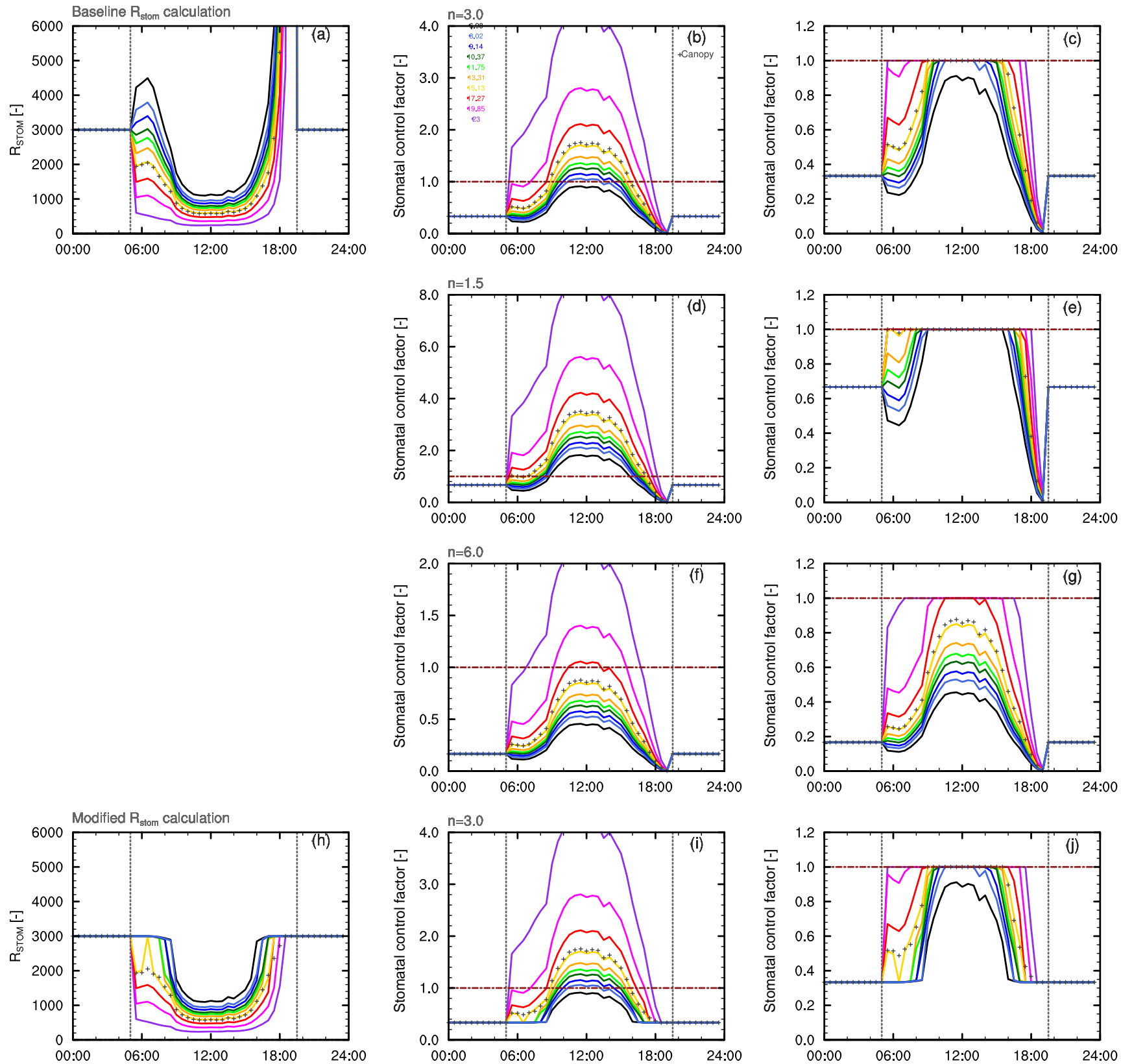

Figure 2. Stomatal control applied to storage emissions. The top row shows the baseline (a) stomatal resistance, (b) stomatal control factor $R_{\mathrm{fct}}$ as calculated in Eq. (10), and (c) the stomatal control factor as calculated in Eq. (11a) and (b), i.e. with a limiting value of 1.0. Coloured lines show the resistances and control factors as a leaf-area-weighted average for each crown space model level across the 10 leaf angle classes. The crosses show the canopy average weighted by foliage fraction in each level. The second and third rows show the effect on $R_{\mathrm{fct}}$ of altering the scaling factor, $n$, in Eq. (10) (d and $\mathbf{f}$ ) and Eq. (11a) and (b) (e and $\mathbf{g}$ ). The bottom row shows the same as the top for the modified stomatal resistance calculations in which "daylight" is assumed to start only when PAR exceeds a threshold of $10.0 \mu \mathrm{mol} \mathrm{m}^{-2} \mathrm{~s}^{-1}$.

(Eq. 10) describes the inverse of $R_{\text {stom }}$, reaching a peak at midday and having a greater value higher in the canopy. As shown in the middle panels $R_{\text {fct }}$ reaches $>1.0$ during the middle of the day for all but the very lowest canopy layers. Modelled stomatal control ( $S$-simulations) therefore enhances emissions of methanol and acetaldehyde above those simulated by traditional emissions algorithms during this time. There is evidence that this may be biologically realistic with stomatal-aperture-limiting emissions from storage pools, leading to increased pool size and hence greater concentration gradients between plant tissue and the surrounding atmosphere (see e.g. Jardine et al., 2008). This in turn drives an increase in emissions above those predicted based on synthesis rates of oVOCs. However, traditional emissions 
models were derived to fit observed emission rates (see e.g. Guenther et al., 1993) and could be assumed to account for this effect.

Hence, a second set of "modified" stomatal control $(R-)$ experiments were performed in which it was assumed that beyond a threshold stomatal aperture, stomatal conductance no longer controls emissions, which continue unhindered once the stomates are considered to be fully open. Beyond this point, emissions from storage pools are regulated by temperature alone according to the relationship in Eq. (2), i.e. $R_{\mathrm{fct}}$ in Eq. (9) takes a value of unity, thus assuming that traditional emissions algorithms correctly capture emission rates during the middle of the day. Within FORCAsT this was modelled using a threshold function:

$R_{\mathrm{fct}}=\frac{3000}{n \cdot R_{\mathrm{stom}}}, R_{\mathrm{fct}}<1.0$

$R_{\mathrm{fct}}=1.0$, at all other times.

The use of the function shown in Eqs. (11a) and (b) limits the temporal extent of stomatal control on methanol and acetaldehyde emissions for most canopy layers to the transition times of day (dawn and dusk) when the stomata are either opening or closing as light levels increase or decrease. This is consistent with results from controlled experiments and observations by Niinemets and Reichstein (2003a) that indicate that stomatal aperture has only a transient effect on the emissions of oVOCs and is negligible under steady-state light conditions. It should be noted however that under the average July radiation conditions, the lower canopy levels do not receive sufficient PAR to reach this threshold value within FORCAsT.

\section{Results}

\subsection{Summary of observations}

July was roughly the middle of the growing season in 2012 with emissions unaffected by springtime leaf flush or autumn senescence. As observed previously at many sites, fluxes of both methanol and acetaldehyde are highly variable, with periods of net positive and net negative exchange (e.g. McKinney et al., 2011; Wohlfahrt et al., 2015; Karl et al., 2005). In prior years, concentrations of methanol at Harvard Forest remained high even outside of the spring emissions peak (McKinney et al., 2011).

Figure 3 shows correlations of the observed daytime (05:00-19:00 EST) fluxes of methanol and acetaldehyde during July 2012 with air temperature, PAR, canopy stomatal conductance, and concentrations of methanol and acetaldehyde. Canopy stomatal conductance for the tower footprint was estimated from energy fluxes measured at Harvard Forest following the methodology of Shuttleworth et al. (1984) to calculate surface resistances. The raw data were highly
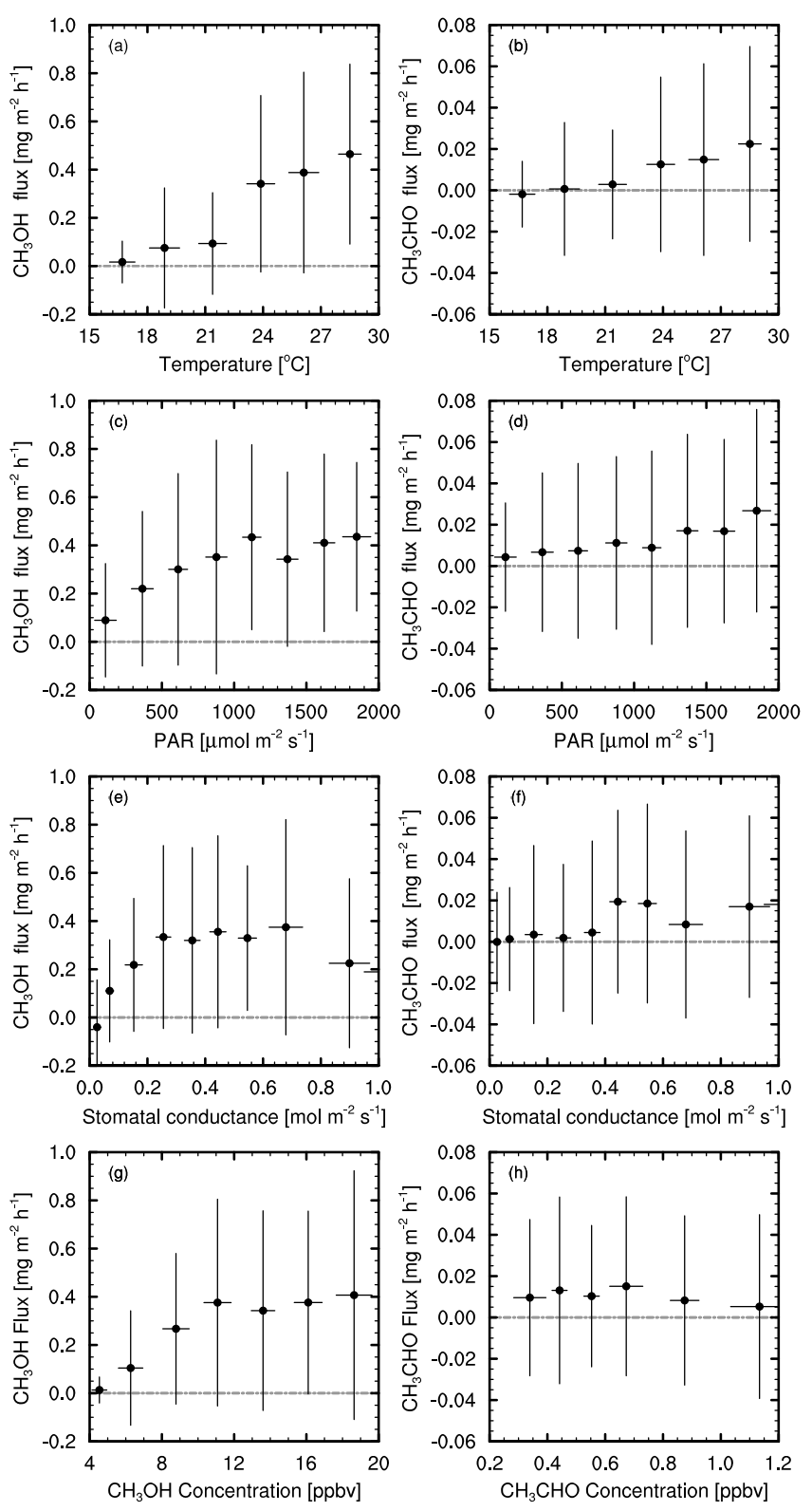

Figure 3. Observed daytime (05:00-19:00 EST) fluxes of methanol (left) for July 2012 vs. (a) air temperature, (c) PAR, (e) canopy stomatal conductance, and (g) methanol concentration (all measured at $29 \mathrm{~m})$. The right hand column (b, d, f, h) shows the same relationships for acetaldehyde. Temperatures were binned in $2.5^{\circ} \mathrm{C}$ intervals, PAR in $250 \mu \mathrm{mol} \mathrm{m}{ }^{-2} \mathrm{~s}^{-1}$, stomatal conductance in $\sim 0.1 \mathrm{~mol} \mathrm{~m}^{-2} \mathrm{~s}^{-1}$, and concentrations in $2.5 \mathrm{ppbv}$ (methanol) and $0.2 \mathrm{ppbv}$ (acetaldehyde) increments. Average values for each bin are marked with circles; vertical and horizontal bars indicate 1 standard deviation above and below the mean in each case. 
scattered, and were therefore binned by the independent variable in each case, with Fig. 3 showing only the mean values (with bars showing \pm 1 standard deviation to give an indication of the variability of the data) for each of these bins for clarity. The weak relationships with each of the environmental variables evident in Fig. 3 illustrate the difficulty in identifying the key processes driving canopy-scale exchanges of oVOCs under varying environmental conditions from observations alone.

Canopy-top fluxes of methanol appear to be positively correlated with temperature (Fig. 3a) and to a lesser extent with PAR (Fig. 3c). The correlation with temperature seems to be exponential as might be expected. The contribution of stomatal conductance to observed methanol fluxes is more difficult to interpret, although the data appear to show a strong linear correlation at low conductance, suggesting that at small stomatal aperture the stomata exert control over fluxes of methanol to the extent that it is observable at the canopy scale. However, it is possible that this correlation instead reflects correlated responses of emissions and stomatal aperture to increasing light and temperature. The positive relationship between canopy-top methanol fluxes and concentrations at low concentration is likely due to the influence of increasing light and temperature, increasing production of methanol at a greater rate than the loss processes (dry deposition to surfaces within the canopy and chemical loss). At higher concentrations, methanol loss rates increase sufficiently to balance production.

Fluxes of acetaldehyde are lower and more variable than those of methanol, and averages are clustered near zero. However, the fluxes do appear to be positively correlated with temperature (Fig. 3b), although the relationship is weaker and does not appear to be exponential. There is no discernible correlation between acetaldehyde fluxes and either PAR (Fig. 3d) or stomatal conductance (Fig. 3f). This might suggest that acetaldehyde emissions are not controlled by stomatal aperture but may rather indicate the influence of the greater number of sources and sinks for acetaldehyde at the spatial and temporal scale of the canopy. Jardine et al. (2008) describe a clear negative correlation between acetaldehyde fluxes and concentrations measured in the laboratory. Fig. $3 \mathrm{~h}$ could be interpreted in a similar way, although the correlation here (at the canopy scale) is far weaker.

The weakness of the observed correlations and the variability of the observed fluxes are a reflection of the complexity of in-canopy processes and interactions, all of which (emissions, photochemical production and loss, and turbulent exchange) are strongly influenced by temperature, while only photolysis and direct foliage emissions are directly dependent on light levels (although the penetration of radiation into the canopy drives both leaf temperature and turbulence).

\subsection{Baseline}

When FORCAsT is driven in default mode with average meteorology and initial conditions for July 2012 and primary emissions of only isoprene and monoterpenes, the model fails to capture either the magnitude or diurnal profile of the observed concentrations and fluxes of methanol and acetaldehyde at $29 \mathrm{~m}$ (Fig. 4a-d, black lines). For both methanol and acetaldehyde, FORCAsT simulates negative fluxes at all times, with a pronounced decrease during daylight hours (Fig. 4a and c). In contrast, fluxes measured by eddy covariance show strongly positive (upward) exchange occurring during the day and fluxes near zero at night. Observed concentrations increase to 12.8 (methanol) and $0.72 \mathrm{ppbv}$ (acetaldehyde) during daylight hours, dipping sharply after dusk and decreasing steadily to a minimum around dawn (Fig. 4b and d). By contrast the baseline modelled concentrations of both compounds decrease throughout the $24 \mathrm{~h}$ period, (Fig. $4 \mathrm{~b}$ and d), suggesting strong daytime sources of both methanol and acetaldehyde within the canopy, which FORCAsT does not simulate with the default model settings.

\subsection{Biogenic emissions of methanol and acetaldehyde ( $E$-simulations)}

Leaf-level measurements of methanol emissions have demonstrated that all $\mathrm{C}_{3}$ vegetation types emit methanol at rates on par with the major terpenoids (Fall and Benson, 1996). Given the lack of other in situ sources of methanol, the diel cycle of fluxes and concentrations that is generally absent from anthropogenic and transported sources, and the magnitude of the underestimation of canopy-top fluxes (ranging from $\sim 0.01$ overnight to $0.7 \mathrm{mg} \mathrm{m}^{-2} \mathrm{~h}^{-1}$ in the early afternoon), it seems likely that there are substantial foliage emissions of methanol at Harvard Forest (see also McKinney et al., 2011). Furthermore, the diurnal profile, strongly reminiscent of isoprene, suggests that the emissions are both light and temperature dependent.

While the magnitude of the missing acetaldehyde fluxes is lower (between $\sim 0.01$ and $0.05 \mathrm{mg} \mathrm{m}^{-2} \mathrm{~h}^{-1}$ ), the diel cycles of both fluxes and concentrations is similar to those of methanol. This again suggests relatively strong leaf-level emissions of acetaldehyde at this site. It is likely that the absolute concentrations and fluxes are lower since primary emissions of acetaldehyde have generally been found to be a factor of 2-10 lower than those of methanol (Seco et al., 2007; Karl et al., 2003; Guenther et al., 2012).

Figure 5 shows the relative contributions of the competing processes driving the evolution of methanol and acetaldehyde within and just above the canopy over the course of the day for the $E$-combo 90 and $E$-combo simulations respectively. Concentrations of both oVOCs (Figs. $5 \mathrm{a}$ and $3 \mathrm{~g}$ ) increase strongly at all levels from a minimum around dawn. In the case of methanol (Fig. 5a) there is a clear maximum just below the top of the canopy corresponding to 

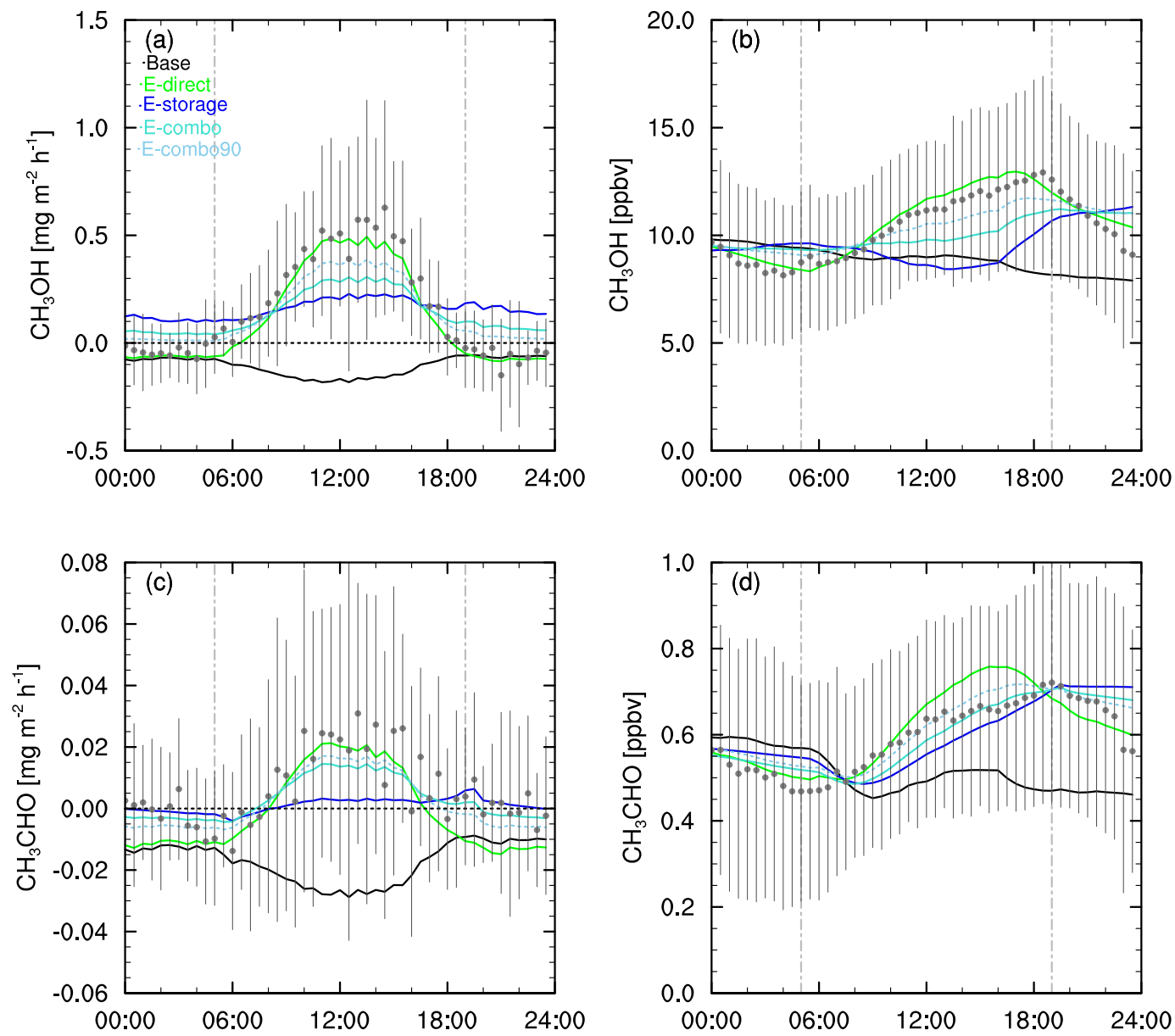

Figure 4. Measured (grey circles with vertical bars indicating 1 standard deviation above and below the mean) and modelled (solid lines) fluxes (left) and concentrations (right) at $29 \mathrm{~m}$ for an average day in July 2012 for methanol (a) fluxes ( $\mathrm{mg} \mathrm{m}^{-2} \mathrm{~h}^{-1}$ ) and (b) concentrations (ppbv) and acetaldehyde (c) fluxes and (d) concentrations. The solid black line shows the baseline model simulation. Coloured lines denote $E$ direct (green), $E$-storage (blue), and $E$-combo (cyan) simulations in which direct, storage, and combination emissions pathways respectively are included. The dashed turquoise line shows the $E$-combo90 (combo emissions with 90 direct and $10 \%$ storage emission pathways) sensitivity test. Dashed grey vertical lines show dawn and dusk. Times shown are Eastern Standard Time (EST).

the most densely foliated level where emissions also peak. This feature is less evident in the case of acetaldehyde (Fig. 5g), demonstrating its greater number of sources and sinks. Chemical production and loss is highest at the top of the canopy and the boundary layer just above due to the higher levels of radiation and temperature driving $\mathrm{OH}$ radical formation and reaction rates. For both oVOCs, it is emissions and deposition, both leaf-level processes governed by the stomata, that dominate production and loss; chemistry contributions are at least an order of magnitude lower. However, both chemistry and turbulent transport contribute to the complexity evident in the evolution of concentrations and fluxes and the high degree of variability seen in the observations (see e.g. Figs. 3 and 5).

Difficulties in simultaneously reconciling both fluxes and concentrations of methanol and acetaldehyde are also likely a result of the complexity of in-canopy processes. Figure 5 shows that the top of the canopy is a region of abrupt transition for the sources and sinks of oVOCs with emissions and deposition limited to the canopy and a sudden change in turbulent mixing above the foliage. The heterogeneity of concentrations, concentration gradients, and fluxes of methanol and acetaldehyde in time and space are evident from Fig. 5, demonstrating that the level at which model and measurements are compared can also affect the measured-modelled bias.

\subsubsection{Methanol}

The effect of introducing the different mechanisms of methanol emissions (simulations $E$-direct, $E$-storage, $E$ combo; Table 5) on fluxes and concentrations of methanol are shown in Fig. 4a and b. Storage emissions (dependent only on temperature) remain relatively high overnight. While 

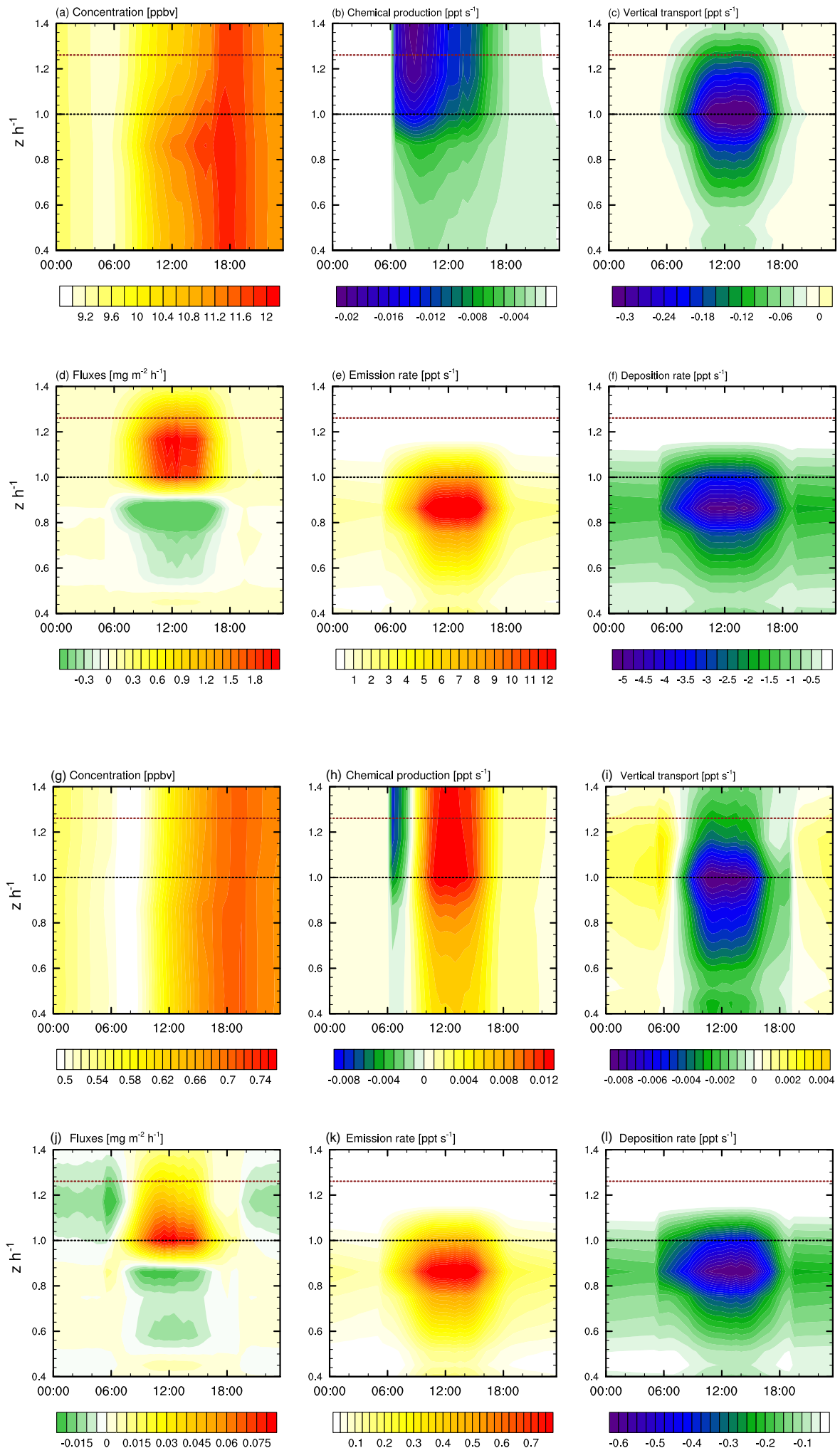

Figure 5. Production and loss within the canopy space for methanol: (a) concentration, (b) chemical production rate (including photolysis), (c) changes in concentration due to vertical mixing, (d) flux, (e) emission rates, and (f) deposition rates of methanol for the $E$-combo90 simulation. Rates are instantaneous in time and space. The vertical axis shows height relative to canopy-top height; times on the horizontal axis are LT. Panels (g)-(l) show the same for acetaldehyde for the $E$-combo simulation. Dashed horizontal lines denote canopy-top height (black) and observation height (red). 

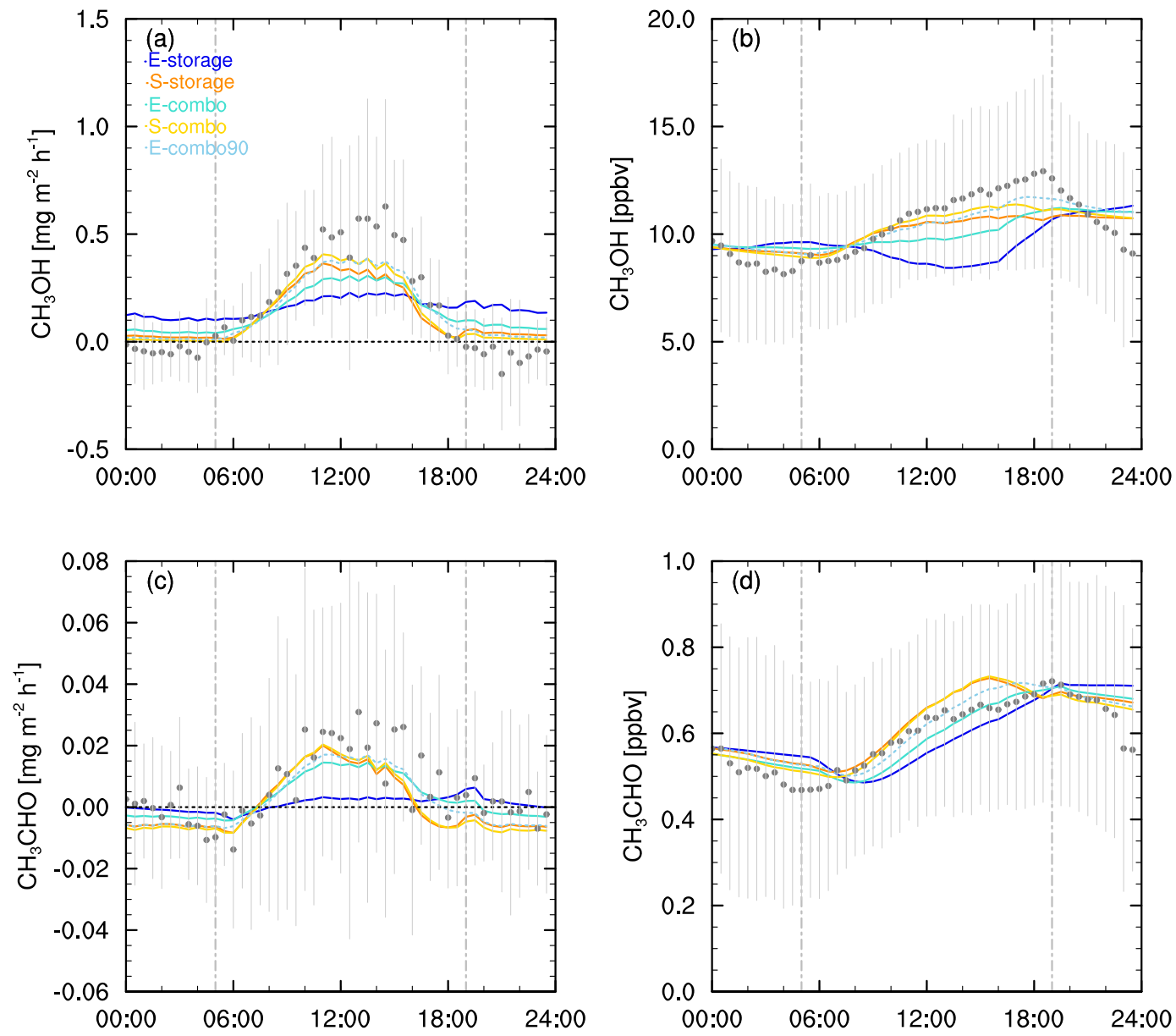

Figure 6. As Fig. 4 with blue lines showing $E$-storage, orange lines $S$-storage simulations, and turquoise and yellow lines showing $E$-combo and $S$-combo simulations respectively. The dashed turquoise line shows the $E$-combo90 sensitivity test. Panels show (a) methanol fluxes, (b) methanol concentrations, (c) acetaldehyde fluxes, and (d) acetaldehyde concentrations at $29 \mathrm{~m}$.

modelled fluxes of methanol are positive when storage emissions are included and peak during the middle of the day, modelled midday fluxes are only around a third of measured fluxes (Fig. 6a, $E$-storage) and modelled night-time fluxes are well above $\left(\sim 0.15-0.20 \mathrm{mg} \mathrm{m}^{-2} \mathrm{~h}^{-1}\right)$ those observed, which are close to but slightly below zero. The diurnal profile of $E$-storage-modelled concentrations is the inverse of measured methanol mixing ratios: elevated at night and decreasing toward the middle of the day (Fig. $6 \mathrm{~b}, E$-storage). This gives further credence to the light dependence of methanol emissions, which has been identified in numerous other forest ecosystems (see e.g. Wohlfahrt et al., 2015; Seco et al., 2015; McKinney et al., 2011).

Direct emissions are intrinsically linked to photosynthesis and are therefore strongly dependent on light as well as temperature. Introducing purely direct emissions of methanol in FORCAsT ( $E$-direct) reproduces the observed diurnal profile of both fluxes and concentrations and succeeds in capturing the pronounced daytime peak and sharp drop-off at night seen in both. Modelled mixing ratios, however, peak slightly in advance of the observed maximum (Fig. 6b, $E$-direct) and do not drop sharply enough after dusk. Modelled fluxes remain negative at night (Fig. 4a, $E$-direct) but are slightly below those observed during the dawn transition period, suggesting that while methanol emissions are light dependent they may not be purely direct emissions (which drop to zero at night). However, the limitations of eddy covariance flux measurement techniques at night may introduce error into the observation-model comparison.

Combo emissions comprising 80 direct and $20 \%$ storage emissions ( $E$-combo) do not reproduce the observed decrease in fluxes and concentrations at night. Modelled nighttime fluxes remain positive and $\sim 0.05-0.1 \mathrm{mg} \mathrm{m}^{-2} \mathrm{~h}^{-1}$ above those observed (Fig. 6a; $E$-combo), although, as noted above, night-time flux measurements usually have the greatest uncertainties due to the potential for stable boundary layers and changes in the flux footprint. Additionally, modelled concentrations do not rise sufficiently during the day (with 
a maximum discrepancy of $\sim 1.5-2$ ppbv or $15 \%$ ) nor drop as steeply as observations after dusk (Fig. 4b, E-combo). Increasing the proportion of direct emissions to $90 \%$ (Fig. $4 \mathrm{a}$ and b) improves the fit of both fluxes and concentrations at all times with maximum daytime differences reduced to $0.2 \mathrm{mg} \mathrm{m}^{-2} \mathrm{~h}^{-1}(\sim 30 \%)$ and $1.0 \mathrm{ppbv}(\sim 8 \%)$ respectively. Modelled concentrations still fail to capture the pronounced changes observed at dawn, although this may be the result of boundary layer dilution and canopy flushing.

The $E$-direct simulation gives the best overall modelmeasurement fit of the emissions sensitivity tests, emphasising the strong light dependence of methanol emissions previously noted. Including direct emissions in FORCAsT simulates the bidirectional fluxes and a diel cycle of concentrations similar to those observed at this site. Such emissions do not fully capture all of the features of the field data, indicating that while methanol emissions are strongly light dependent, traditional models of primary biogenic emissions (e.g. MEGAN; Guenther et al., 2012) may not fully account for the fundamental processes driving methanol exchange between the canopy and atmosphere even when a small contribution from storage pools (e.g. $E$-combo90) is included. However, it should be noted that the fluxes especially represent instantaneous assessments of a situation that rapidly fluctuates in both time and space, which may in part account for the discrepancies between model and measurements.

\subsubsection{Acetaldehyde}

Similar to methanol, introducing storage-only emissions of acetaldehyde does not capture the peak in fluxes during the day (Fig. 4c, E-storage), suggesting that acetaldehyde emissions are also light dependent. Modelled concentrations are close to those observed during daylight hours in both magnitude and profile, with a maximum difference of $\sim 0.2 \mathrm{ppbv}$ (15\%), but they do not reproduce the observed drop in concentration just after dusk nor the rapid increase after dawn (Fig. 4d, E-storage). However, the greater complexity of acetaldehyde production and loss on the timescales involved in canopy-atmosphere exchange makes interpretation of the concentrations more difficult.

Introducing purely direct emissions of acetaldehyde ( $E$ direct) has the same effect as for methanol. Fluxes are strongly negative at night in FORCAsT (around 0.01$0.015 \mathrm{mg} \mathrm{m}^{-2} \mathrm{~h}^{-1}$ below observed fluxes; Fig. 4c, $E$-direct) and concentrations rise too quickly during the day, peaking around $4 \mathrm{~h}$ earlier and $\sim 0.10 \mathrm{ppbv}(\sim 15 \%)$ higher than measured mixing ratios (Fig. 4d, $E$-direct) with a maximum overestimation of $\sim 0.15 \mathrm{ppbv}(\sim 25 \%)$. The steep nighttime drop in observed fluxes and concentrations is reflected (although overestimated) in the model, but overall the simulations suggest acetaldehyde emissions are not purely direct.

In contrast to methanol, acetaldehyde fluxes are better represented by the inclusion of combo emissions comprising $80 \%$ direct emissions (Fig. 4c, E-combo). This captures the diurnal profile of the observations, although not the midday peak, and does not exhibit the same variability in fluxes around dawn and dusk (which may be attributable to the previously described limitations of eddy covariance at these times). Modelled concentrations are within $\sim 0.01 \mathrm{ppbv}$ of those observed during daylight hours and drop quickly after dusk (Fig. 4d, E-combo). When the proportion of direct emissions is increased to $90 \%$, concentrations peak in the late afternoon when measured mixing ratios decline (Fig. 4d, $E$-combo90). The maximum discrepancy is around half that of $E$-direct, and the night-time decrease in mixing ratios is well captured. Daytime fluxes are similar to those of the $E$-combo simulation but decrease more sharply in the afternoon and are lower overnight $\left(\sim 0.05 \mathrm{mg} \mathrm{m}^{-2} \mathrm{~h}^{-1}\right.$ below observations). None of the simulations capture the observed dip in concentration in the late afternoon. However, the results suggest that the canopy-atmosphere exchange of acetaldehyde may be best represented using the combination of emissions of traditional emissions models, with a "lightdependent" fraction of $80 \%$ as currently suggested (Guenther et al., 2012).

\subsection{Effect of stomatal conductance on modelled emissions ( $S$-simulations)}

We now test the effects of stomatal control on the storagebased emissions mechanism by including stomatal regulation in the storage and combo emissions algorithms. These simulations effectively introduce a degree of light dependence to releases of VOCs from storage pools, although it should be noted that the dependence on PAR introduced in this way is not as strong as for direct emissions. We first present and discuss the results of incorporating stomatal control throughout the day (i.e. the $S$-simulations using $R_{\mathrm{fct}}$ as shown in Eq. 10) for both methanol and acetaldehyde. The effects of modifying the control factor (i.e. the $R$-simulations using $R_{\mathrm{fct}}$ as shown in Eq. 11a and b) are described in Sect. 3.5.

\subsubsection{Methanol}

The inclusion of stomatal control of methanol emissions from storage structures into FORCAsT improves the fit of modelled-to-observed fluxes of methanol for both simulations that include storage-type emissions, i.e. $S$-storage vs. $E$-storage and $S$-combo vs. $E$-combo (Fig. 6a). For $100 \%$ storage emissions ( $S$-storage), daytime fluxes are enhanced, and they exhibit the pronounced midday peak of the measurements (generally $<0.2 \mathrm{mg} \mathrm{m}^{-2} \mathrm{~h}^{-1}$ below those observed). Night-time fluxes are reduced by $\sim 0.1-0.15 \mathrm{mg} \mathrm{m}^{-2} \mathrm{~h}^{-1}$, bringing them much closer to observations, but modelled fluxes are still positive at all times. Although modelled concentrations now show a rapid increase in the morning, they plateau at around 11:00 EST and fail to match either observed late afternoon peak or subsequent night-time drop, 
indicating a dependence on light that is not adequately represented by including stomatal control.

Modelled fluxes and concentrations for combo emissions (20\% storage emissions) with stomatal control (Fig. 6a, Scombo) mirror those for $S$-storage, although fluxes remain slightly higher during the middle of the day and drop a little closer to zero at night, and concentrations continue to rise until around 16:00 EST. However, the diurnal profile of methanol concentrations simulated by $E$-combo 90 emissions without stomatal control is closer to the observed than either of the simulations incorporating stomatal control, and $100 \%$ direct emissions still provides the best overall fit.

\subsubsection{Acetaldehyde}

The effects of including stomatal control of emissions of acetaldehyde from storage pools (Fig. 6c and d) are similar to those described above for methanol. For $100 \%$ storage ( $S$-storage vs. $E$-storage) emissions the diurnal profile of modelled acetaldehyde fluxes is a good fit to observations (Fig. 6c), with a pronounced peak during the middle of the day $\left(\sim 0.005-0.01 \mathrm{mg} \mathrm{m}^{-2} \mathrm{~h}^{-1}\right.$ (maximum 0.03 ) below measured fluxes) and dropping below zero overnight (again $\sim 0.005-0.01 \mathrm{mg} \mathrm{m}^{-2} \mathrm{~h}^{-1}$ below measurements). Modelled concentrations increase too rapidly during the day, peaking $\sim 0.15 \mathrm{ppbv}(\sim 25 \%)$ above those observed and $\sim 4$ h earlier, but they do capture the night-time decrease in concentrations seen in the observations (Fig. 6d).

Model output for the $S$-combo simulation is almost identical to that for $S$-storage described above, with the two diverging only at night when the combo emissions are lower, reducing fluxes and, to a lesser extent, concentrations of acetaldehyde. Although introducing stomatal control of emissions from storage pools improves the magnitude and diurnal profile of modelled fluxes, acetaldehyde exchanges at Harvard Forest do not show a strong dependence on stomatal conductance at the canopy scale. Instead they are better represented by the use of traditional emissions models, with a proportion of emissions from storage pools and the remainder via direct release (with the best fit given by 80 direct and $20 \%$ storage, i.e. $E$-combo). This is in agreement with the theoretical conclusions reached by Niinemets and Reichstein (2003b) and the experimental and field results from Kesselmeier (2001) and Kesselmeier et al. (1997). Jardine et al. (2008) report strong evidence of stomatal control at the leaf and branch level and present field measurements that appear to demonstrate that stomatal regulation is relevant at the ecosystem scale for forests in the USA. While our results do not support this conclusion, the authors did report large differences in the effect of stomatal aperture between tree species (Jardine et al., 2008), which may help explain the apparent contradiction.

\subsection{Threshold stomatal control ( $R$-simulations)}

In the $R$-simulations, the stomatal control function was modified to limit stomatal regulation of storage emissions to transition periods as outlined in Sect. 2.3.3. This is consistent with laboratory-based observations of transient emissions bursts associated with light-dark transitions, assuming in effect that there is a point at which the stomatal aperture is sufficient to no longer be a limiting factor. After this point, we set the stomatal control factor to unity to ensure that emissions are no longer dependent on stomatal aperture. This restricts differences between emissions, and therefore fluxes and concentrations, modelled in the $R$ - and $E$-simulations to periods around dawn and dusk.

\subsubsection{Methanol}

For both $R$-storage and $R$-combo simulations, methanol fluxes now show a dip just after dawn and again in the late afternoon, reflecting the period of time when the stomata are partially open (Fig. 7a) but do not otherwise diverge from $E$-storage or $E$-combo. Concentrations still match neither the magnitude nor diurnal profile exhibited by the measurements, decreasing during the day but taking longer to recover in the late afternoon (Fig. 7b). The effect is more pronounced for $100 \%$ storage emissions, but methanol fluxes and concentrations measured above the canopy at Harvard Forest are still most closely matched with the $E$-direct emissions pathway (Fig. 7a, b).

\subsubsection{Acetaldehyde}

By contrast, acetaldehyde fluxes for the $R$-storage simulation show very little change from $E$-storage until late morning (Fig. 7c), when $R$-storage fluxes are nearly double those modelled in $E$-storage but remain well below those observed. Following a steep decline in fluxes in the afternoon to a minimum just before dusk, the post-dusk spike in fluxes previously noted in the $100 \%$ storage emissions simulations is enhanced. Acetaldehyde concentrations for $R$-storage differ little from $E$-storage during the day but remain elevated at night (Fig. 7d). Introducing stomatal regulation to combo emissions (Fig. 7c, d; $R$-combo vs. $E$-combo) has little effect on either fluxes or concentrations. Observed acetaldehyde fluxes and concentrations are still best reflected by $E$ combo traditional emissions algorithms without explicit parameterisation of stomatal regulation.

\subsection{Scaling factor, $n$}

The temporally limited effect of stomatal control in our model simulations is consistent with conclusions drawn from a theoretical study based on results from detailed laboratory experiments (Niinemets and Reichstein, 2003b, a), showing that the stomatal control of biogenic VOC emission rates occurs over short timescales. This suggests that regulation of 

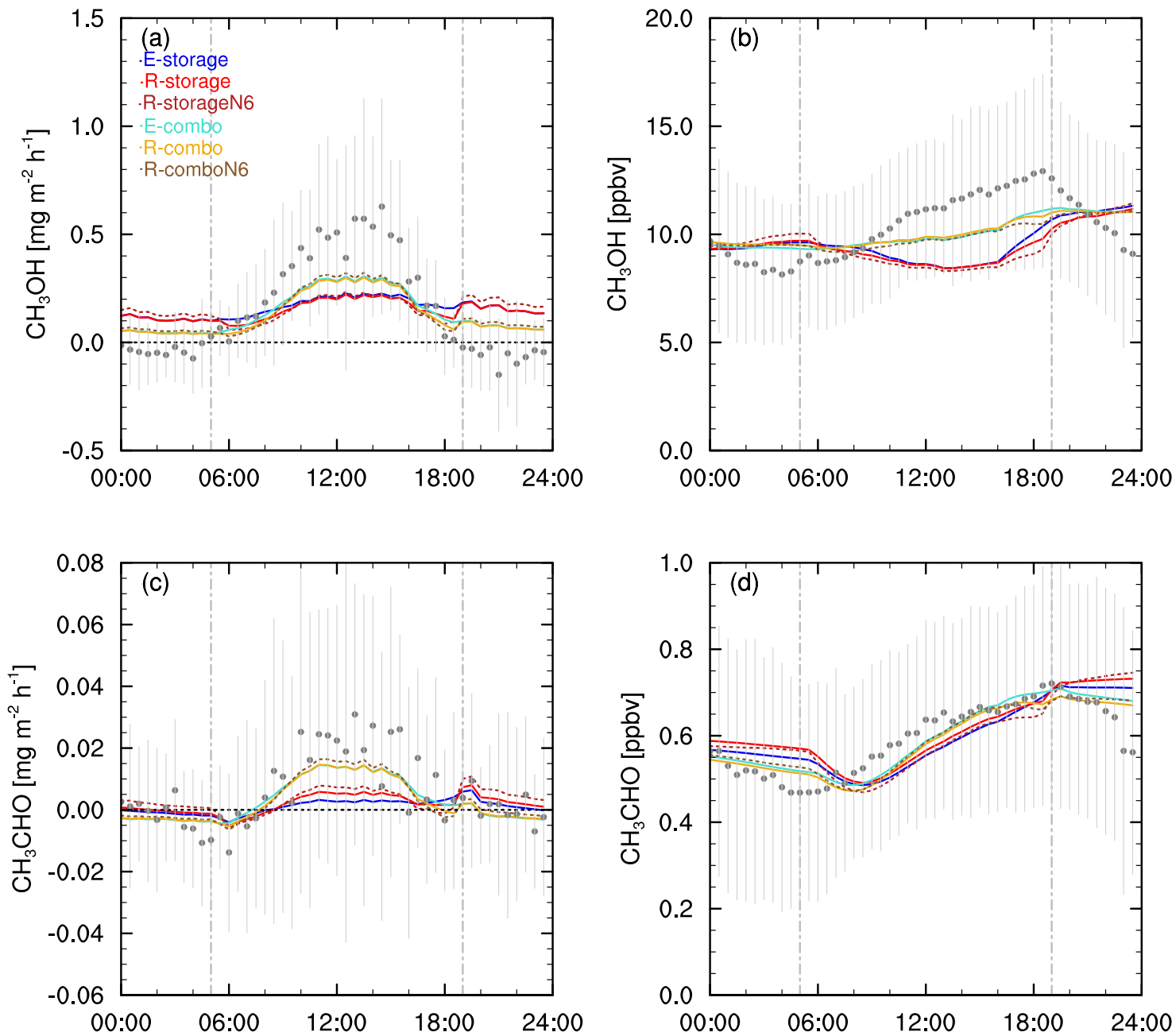

Figure 7. Simulations of modified stomatal control of storage emissions ( $R$-). Blue and turquoise lines show $E$-storage and $E$-combo as in Fig. 6. Red ( $R$-storage) and dashed, dark red $(R$-storageN6) lines show the effects on $100 \%$ storage emissions for scaling factor $n=3$ and $n=6$ respectively. Gold ( $R$-combo) and dashed brown $(R$-comboN6) lines show the same for combo emissions ( $20 \%$ storage). Panels show (a) methanol fluxes, (b) methanol concentrations, (c) acetaldehyde fluxes, and (d) acetaldehyde concentrations at $29 \mathrm{~m}$ for an average day in July 2012.

emissions by stomata occurs over too brief of a period to be of significance at an ecosystem scale for highly volatile VOCs. However, Niinemets and Reichstein (2003a, b) postulate that emission rates of highly water-soluble VOCs such as methanol are subject to stomatal regulation over longer timescales, potentially modifying emissions over scales relevant to canopy-atmosphere exchange. Niinemets and Reichstein (2003b) concluded that the strength and persistence of stomatal control on leaf-level emissions scaled with the Henry's law coefficient. Hence, in the final stomatal control simulations ( $R$-storageN15, $R$-storageN6, $R$ comboN15, and $R$-combo6) we scaled the "degree" of regulation by altering the scaling factor, $n$, in Eq. (11a) and (b) (see Table 5), altering both the magnitude and duration of stomatal control (i.e. the time taken for $R_{\mathrm{fct}}$ in Eq. (10) to reach values over 1.0) as shown in Fig. 2.
Changing $n$ makes little difference to modelled fluxes or concentrations of methanol or acetaldehyde (Fig. 7; $R$-storageN6 vs. $R$-storage and $R$-comboN6 vs. $R$ combo). Night-time fluxes were enhanced slightly $\left(\sim 0.02 \mathrm{mg} \mathrm{m}^{-2} \mathrm{~h}^{-1}\right.$ for $100 \%$ storage emissions and $\sim 0.01 \mathrm{mg} \mathrm{m}^{-2} \mathrm{~h}^{-1}$ for $80 \%$ storage emissions) when $n$ was doubled. Concentrations of both were reduced in the late afternoon, reflecting the extended duration of control of emission but the effect is short-lived and is not reflected in the observations. Changes at all times were negligible when $n$ was reduced to 1.5 (not shown).

These results are consistent with observations of canopy structure at Harvard Forest; foliage is densest in the upper canopy. Figure 2 shows that changing $n$ has the biggest impact on the lower canopy levels where light is limited, foliage biomass is low (over $50 \%$ of the biomass is found in 
the top $20 \%$ of the canopy at Harvard Forest; Parker, 1998), and emission rates are small.

\section{Conclusions}

When light-dependent emissions of methanol and acetaldehyde were included, the FORCAsT canopy-atmosphere exchange model successfully simulated the bidirectional exchange of methanol and acetaldehyde at Harvard Forest, a northern mid-latitude mixed deciduous woodland. Overall, we find that the bidirectional exchange of methanol at Harvard Forest is well captured with the algorithms currently used for modelling foliage emissions of oVOCs (e.g. MEGAN; Guenther et al., 2012) assuming $100 \%$ lightdependent (direct) emissions. In the case of acetaldehyde, modelled concentrations prove robust, with a relatively good fit to observations for all emissions scenarios employed here, likely due to the greater number of chemical sources and sinks of acetaldehyde in comparison to methanol. However, we find that canopy-top acetaldehyde fluxes at this site are also best modelled with traditional emissions algorithms. In contrast to methanol, however, acetaldehyde emissions at Harvard Forest appear to be derived from both direct synthesis and storage pools, with $80 \%$ direct emissions giving the best overall fit.

The light dependence of both methanol and acetaldehyde emissions at the leaf level has been ascribed to the stomatal control of diffusion from storage pools, which would otherwise be expected to be dependent on temperature alone. We incorporated a simple parameterisation of the regulation of emissions according to stomatal aperture into FORCAsT to determine how stomatal control affects canopy-top fluxes and concentrations of methanol and acetaldehyde at this site. While we found that some simulations that included stomatal regulation of emissions showed a good fit to measured fluxes, none proved effective in reproducing both the observed concentrations and fluxes.

Instead, our simulations show that current emissions algorithms are capable of capturing fluxes and concentrations of both methanol and acetaldehyde near the top of the canopy and are therefore appropriate for use at the ecosystem scale. Our results further demonstrate that canopy-top fluxes of methanol and acetaldehyde are determined primarily by the relative strengths of foliage emissions and dry deposition, indicating that 3-D atmospheric chemistry and transport models must include a treatment of deposition that is not only dynamically intrinsically linked to land surface processes but is consistent with the emissions scheme.

Our results show that it is possible to model canopy-top fluxes of methanol and acetaldehyde, and to capture bidirectional exchange without the need to include direct representations of stomatal control of emissions. This contrast to experimental evidence highlights the complexity of competing in-canopy processes, which act to buffer the stomatal control of emissions observed at the leaf and branch level. Stomatal aperture affects emissions over too short of a timescale to be observable at the canopy scale when other sources and sinks are fully accounted for. The times around dawn and dusk, when stomatal regulation has been demonstrated to occur, are also associated with rapid changes in chemistry and atmospheric dynamics, which likely outweigh the small differences in emission rates. Our findings indicate that the inclusion of a light-dependent fraction in current emissions algorithms (e.g. Guenther et al., 2012) captures the changes in storage emissions due to changes in stomatal aperture sufficiently well to simulate exchanges at the canopy scale.

Given that observed methanol fluxes appear strongly correlated with stomatal conductance at small stomatal apertures, it is perhaps surprising that we found no evidence supporting the suggestion that stomatal control of methanol emissions is observable at the canopy scale. We ascribe this to the use of empirically derived emissions algorithms combined with the similar and competing strong dependence of methanol deposition on stomatal conductance.

Our results highlight the importance of the holistic treatment and coupling between land surface sources and sinks. The use of explicit and consistent dynamic representations of emissions and deposition, which dominate the in-canopy budgets for these longer-lived oVOCs, are needed in atmospheric chemistry and transport models. Such an approach would adequately account for the role of the stomata in both processes and allow bidirectional exchange to be successfully simulated without the need for including either leaflevel process detail or a compensation point.

However, this study also demonstrates the need for a better understanding and representation of the complex relationship between turbulence, fluxes, and concentration gradients within and above the forest canopy. Such understanding can only be achieved through further modelling studies at a range of scales in combination with robust measurements of concentrations and fluxes of VOCs, their primary oxidants, and oxidation products at multiple heights within the forest canopy.

\section{Data availability}

Data collected and analysed during this study are available from the authors. Observed fluxes and concentrations of methanol and acetaldehyde should be requested from Karena McKinney (kamckinney@seas.harvard.edu) and model output data from the corresponding author (k.s.ashworth1@lancaster.ac.uk). Meteorological and ecosystem data from the long-term monitoring of Harvard Forest are accessible via the Harvard Forest data archive (long-term measurements; http://harvardforest.fas.harvard. edu:8080/exist/apps/datasets/da-long.html) specifically datasets HF004 (http://harvardforest.fas.harvard.edu: 8080/exist/apps/datasets/showData.html?id=hf004), 
HF066 (http://harvardforest.fas.harvard.edu:8080/exist/ apps/datasets/showData.html?id=hf066), and HF069 (http://harvardforest.fas.harvard.edu:8080/exist/apps/ datasets/showData.html?id=hf069). Flux and concentration data from the 2012 intensive field campaign will be transferred to the Harvard Forest data archive for long-term storage and access in the future.

Acknowledgements. This material is based upon work supported by the National Science Foundation under Grant No. AGS 1242203. The Harvard Forest Flux Tower is an AmeriFlux core site funded in part by the US Department of Energy's Office of Science and additionally by the National Science Foundation as part of the Harvard Forest Long Term Ecological Research site.

Edited by: L. Ganzeveld

Reviewed by: two anonymous referees

\section{References}

Ashworth, K., Chung, S. H., Griffin, R. J., Chen, J., Forkel, R., Bryan, A. M., and Steiner, A. L.: FORest Canopy Atmosphere Transfer (FORCAsT) 1.0: a 1-D model of biosphereatmosphere chemical exchange, Geosci. Model Dev., 8, 37653784, doi:10.5194/gmd-8-3765-2015, 2015.

Baldocchi, D.: A multi-layer model for estimating sulfur dioxide deposition to a deciduous oak forest canopy, Atmos. Environ., 22, 869-884, doi:10.1016/0004-6981(88)90264-8, 1988.

Baldocchi, D. D.: Assessing the eddy covariance technique for evaluating carbon dioxide exchange rates of ecosystems: past, present and future, Glob. Change Biol., 9, 479-492, doi:10.1046/j.1365-2486.2003.00629.x, 2003.

Baldocchi, D.: Measuring fluxes of trace gases and energy between ecosystems and the atmosphere - the state and future of the eddy covariance method, Glob. Change Biol., 20, 3600-3609, doi:10.1111/gcb.12649, 2014.

Baldocchi, D. D., Hicks, B. B., and Camara, P.: A canopy stomatal resistance model for gaseous deposition to vegetated surfaces, Atmos. Environ., 21, 91-101, 1987.

Barford, C. C., Wofsy, S. C., Goulden, M. L., Munger, J. W., Pyle, E. H., Urbanski, S. P., Hutyra, L., Saleska, S. R., Fitzjarrald, D., and Moore, K.: Factors Controlling Long- and Short-Term Sequestration of Atmospheric $\mathrm{CO}_{2}$ in a Mid-latitude Forest, Science, 294, 1688-1691, doi:10.1126/science.1062962, 2001.

Blackadar, A. K.: High-resolution models of the planetary boundary layer, in: Advances in Environmental Science and Engineering, Gordon and Breech Science Publishers, Inc., NewYork, USA, 1, 50-85, 1979.

Bryan, A. M., Bertman, S. B., Carroll, M. A., Dusanter, S., Edwards, G. D., Forkel, R., Griffith, S., Guenther, A. B., H ansen, R. F., Helmig, D., Jobson, B. T., Keutsch, F. N., Lefer, B. L., Pressley, S. N., Shepson, P. B., Stevens, P. S., and Steiner, A. L.: Incanopy gas-phase chemistry during CABINEX 2009: sensitivity of a 1-D canopy model to vertical mixing and isoprene chemistry, Atmos. Chem. Phys., 12, 8829-8849, doi:10.5194/acp-12-88292012, 2012.
Bryan, A. M., Cheng, S. J., Ashworth, K., Guenther, A. B., Hardiman, B. S., Bohrer, G., and Steiner, A. L.: Forestatmosphere BVOC exchange in diverse and structurally complex canopies: 1-D modeling of a mid-successional forest in northern Michigan, Atmos. Environ., 120, 217-226, doi:10.1016/j.atmosenv.2015.08.094, 2015.

Butler, T. M., Taraborrelli, D., Brühl, C., Fischer, H., Harder, H., Martinez, M., Williams, J., Lawrence, M. G., and Lelieveld, J.: Improved simulation of isoprene oxidation chemistry with the ECHAM5/MESSy chemistry-climate model: lessons from the GABRIEL airborne field campaign, Atmos. Chem. Phys., 8, 4529-4546, doi:10.5194/acp-8-4529-2008, 2008.

Chen, J. and Griffin, R. J.: Modeling Secondary Organic Aerosol Formation From Oxidation of $\alpha$-Pinene, $\beta$ Pinene, and d-Limonene, Atmos. Environ., 39, 7731-7744, doi:10.1016/j.atmosenv.2005.05.049, 2005.

Environmental Protection Agency (EPA): National and Regional Air Quality Trends, vailable at: https://gispub.epa.gov/air/ trendsreport/2016/ (last access: 10 December 2016), 2015.

Fall, R. and Benson, A.: Leaf Methanol - the Simplest Natural Product From Plants, Trends Plant Sci., 1, 296-301, doi:10.1016/S1360-1385(96)88175-0, 1996.

Fischer, E. V., Jacob, D. J., Yantosca, R. M., Sulprizio, M. P., Millet, D. B., Mao, J., Paulot, F., Singh, H. B., Roiger, A., Ries, L., Talbot, R. W., Dzepina, K., and Pandey Deolal, S.: Atmospheric peroxyacetyl nitrate (PAN): a global budget and source attribution, Atmos. Chem. Phys., 14, 2679-2698, doi:10.5194/acp-142679-2014, 2014.

Forkel, R., Klemm, O., Graus, M., Rappenglück, B., Stockwell, W. R., Grabmer, W., Held, A., Hansel, A., and Steinbrecher, R.: Trace gas exchange and gas phase chemistry in a Norway spruce forest: A study with a coupled 1-dimensional canopy atmospheric chemistry emission model, Atmos. Environ., 40, 28 42, doi:10.1016/j.atmosenv.2005.11.070, 2006.

Folberth, G. A., Hauglustaine, D. A., Lathière, J., and Brocheton, F.: Interactive chemistry in the Laboratoire de Météorologie Dynamique general circulation model: model description and impact analysis of biogenic hydrocarbons on tropospheric chemistry, Atmos. Chem. Phys., 6, 2273-2319, doi:10.5194/acp-62273-2006, 2006.

Ganzeveld, L., Eerdekens, G., Feig, G., Fischer, H., Harder, H., Königstedt, R., Kubistin, D., Martinez, M., Meixner, F. X., Scheeren, H. A., Sinha, V., Taraborrelli, D., Williams, J., VilàGuerau de Arellano, J., and Lelieveld, J.: Surface and boundary layer exchanges of volatile organic compounds, nitrogen oxides and ozone during the GABRIEL campaign, Atmos. Chem. Phys., 8, 6223-6243, doi:10.5194/acp-8-6223-2008, 2008.

Gao, W., Wesely, M. L., and Doskey, P. V.: Numerical Modeling of the Turbulent Diffusion and Chemistry of $\mathrm{NO}_{x}, \mathrm{O}_{3}$, Isoprene, and Other Reactive Trace Gases in and Above a Forest Canopy, J. Geophys. Res., 98, 18339-18353, 1993.

Geron, C., Rasmussen, R., Arnts, R. R., and Guenther, A.: A Review and Synthesis of Monoterpene Speciation From Forests in the United States, Atmos. Environ., 34, 1761-1781, 2000.

Goel, N. S. and Strebel, D. E.: Simple beta distribution representation of leaf orientation in vegetation canopies, Agron. J., 76, 800-802, 1984.

Goldstein, A. H., Wofsy, S. C., and Spivakovsky, C. M.: Seasonal Variations of Nonmethane Hydrocarbons in Rural New England: 
Constraints on $\mathrm{OH}$ Concentrations in Northern Midlatitudes, J. Geophys. Res., 100, 21023-21033, doi:10.1029/95JD02034, 1995.

Goldstein, A. H., Goulden, M. L., Munger, J. W., Wofsy, S. C., and Geron, C. D.: Seasonal course of isoprene emissions from a midlatitude deciduous forest, J. Geophys. Res., 103, 31045-31056 , doi:10.1029/98JD02708, 1998.

Goulden, M L., Munger, J. W., Fan, S. M., Daube, B. C., and Wofsy, S. C.: Measurements of carbon sequestration by long-term eddy covariance: methods and a critical evaluation of accuracy, Glob. Change Biol., 2, 169-182, 1996.

Graus, M., Müller, M., and Hansel, A.: High resolution PTRTOF: quantification and formula confirmation of VOC in real time, J. Am. Soc. Mass. Spectr., 21, 1037-1044, doi:10.1016/j.jasms.2010.02.006, 2010.

Griffin, R. J., Dabdub, D., and Seinfeld, J. H.: Secondary Organic Aerosol 1. Atmospheric Chemical Mechanism for Production of Molecular Constituents, J. Geophys. Res., 107, 4332, doi:10.1029/2001JD000541, 2002.

Griffin, R. J., Dabdub, D., and Seinfeld, J. H.: Development and Initial Evaluation of a Dynamic Species-Resolved Model for Gas Phase Chemistry and Size-Resolved Gas/Particle Partitioning Associated with Secondary Organic Aerosol Formation, J. Geophys. Res., 110, D05304, doi:10.1029/2004JD005219, 2005.

Grote, R. and Niinemets, Ü.: Modeling Volatile Isoprenoid Emissions - a Story with Split Ends, Plant Biol., 10, 8-28, doi:10.1055/s-2007-964975, 2008.

Gu, L., Falge, E. M., Boden, T., Baldocchi, D. D., Black, T.A., Saleska, S. R., Suni, T., Verma, S. B., Vesala, T., Wofsy, S. C., and $\mathrm{Xu}, \mathrm{L}$.: Objective threshold determination for nighttime eddy flux filtering, Agr. Forest Meteorol., 128, 179-197, doi:10.1016/j.agrformet.2004.11.006, 2005.

Guenther, A., Hewitt, C. N. Erickson, D., Fall, R., Geron, C., Graedel, T., Harley, P., Klinger, L., Lerdau, M., McKay, W. A., Pierce, T., Scholes, B., Steinbrecher, R., Tallamraju, R., Taylor, J., and Zimmerman, P.: A Global Model of Natural Volatile Organic Compound Emissions, J. Geophys. Res., 100, 8873-8892, doi:10.1029/94JD02950, 1995.

Guenther, A., Karl, T., Harley, P., Wiedinmyer, C., Palmer, P. I., and Geron, C.: Estimates of global terrestrial isoprene emissions using MEGAN (Model of Emissions of Gases and Aerosols from Nature), Atmos. Chem. Phys., 6, 3181-3210, doi:10.5194/acp-63181-2006, 2006.

Guenther, A. B., Zimmerman, P. R., Harley, P. C., Monson, R. K., and Fall, R.: Isoprene and Monoterpene Emission Rate Variability - Model Evaluations and Sensitivity Analyses, J. Geophys. Res., 98, 12609-12617, doi:10.1029/93JD00527, 1993.

Guenther, A. B., Jiang, X., Heald, C. L., Sakulyanontvittaya, T., Duhl, T., Emmons, L. K., and Wang, X.: The Model of Emissions of Gases and Aerosols from Nature version 2.1 (MEGAN2.1): an extended and updated framework for modeling biogenic emissions, Geosci. Model Dev., 5, 1471-1492, doi:10.5194/gmd-51471-2012, 2012.

Harley, P., Greenberg, J., Niinemets, Ü., and Guenther, A.: Environmental controls over methanol emission from leaves, Biogeosciences, 4, 1083-1099, doi:10.5194/bg-4-1083-2007, 2007.

Heikes, B. G., Chang, W. N., Pilson, M. E. Q., Swift, E., Singh, H. B., Guenther, A., Jacob, D. J., Field, B.D., Fall, R., Riemer, D., and Brand, L.: Atmospheric Methanol Budget and Ocean Implication, Global Biogeochem. Cy., 16, 801-813, doi:10.1029/2002GB001895, 2002.

Helmig, D., Klinger, L. F., Guenther, A., Harley, P., Geron, C., and Zimmerman, P.: Biogenic Volatile Organic Compound Emissions (BVOCs) 1. Identifications From Three Continental Sites in the US, Chemosphere, 38, 2163-2187, 1999.

Horii, C. V., Munger, J. W., Wofsy, S. C., Zahniser, M., Nelson, D., and McManus, J. B.: Fluxes of nitrogen oxides over a temperate deciduous forest, J. Geophys. Res., 109, D08305, doi:10.1029/2003JD004326, 2004.

Hu, L., Millet, D. B., Mohr, M. J., Wells, K. C., Griffis, T. J., and Helmig, D.: Sources and seasonality of atmospheric methanol based on tall tower measurements in the US Upper Midwest, Atmos. Chem. Phys., 11, 11145-11156, doi:10.5194/acp-1111145-2011, 2011.

Huve, K., Christ, M., Kleist, E., Uerlings, R., Niinemets, Ü., Walter, A., and Wildt, J.: Simultaneous Growth and Emission Measurements Demonstrate an Interactive Control of Methanol Release by Leaf Expansion and Stomata, J. Exp. Bot., 58, 1783-1793, doi:10.1093/jxb/erm038, 2007.

Jacob, D. J., Field, B. D., Jin, E. M., Bey, I., Li, Q., Logan, J. A., and Yantosca R.M.: Atmospheric Budget of Acetone, J. Geophys. Res., 107, 4100, doi:10.1029/2001JD000694, 2002.

Jardine, K., Harley, P., Karl, T., Guenther, A., Lerdau, M., and Mak, J. E.: Plant physiological and environmental controls over the exchange of acetaldehyde between forest canopies and the atmosphere, Biogeosciences, 5, 1559-1572, doi:10.5194/bg-5-15592008, 2008.

Jarvis, P. G.: The interpretation of the variations in leaf water potential and stomatal conductance found in canopies in the field, Philos. T. R. Soc. B, 273, 593-610, 1976.

Jarvis, P. G., Massheder, J. M., Hale, S. E., Moncrieff, J. B., Rayment, M., and Scott, S. L.: Seasonal variation of carbon dioxide, water vapor, and energy exchanges of a boreal black spruce forest, J. Geophys. Res., 102, 28953-28966, doi:10.1029/97JD01176, 1997.

Jordan, A., Haidacher, S., Hanel, G., Hartungen, E., Herbig, J., Märk, L., Schottkowsky, R., Seehauser, H., Sulzer, P., and Märk, T. D.: An online ultra-high sensitivity proton-transfer-reaction mass-spectrometer combined with switchable reagent ion capability (PTR + SRI - MS), Int. J. Mass. Spectrom., 286, 32-38, doi:10.1016/j.ijms.2009.06.006, 2009a.

Jordan, A., Haidacher, S., Hanel, G., Hartungen, E., Märk, L., Seehauser, H., Schottkowsky, R., Sulzer, P., and Märk, T. D.: A high resolution and high sensitivity proton-transfer-reaction time-of flight mass spectrometer (PTR-TOF-MS), Int. J. Mass. Spectrom., 286, 122-128, doi:10.1016/j.ijms.2009.07.005, 2009b.

Karl, T., Curtis, A. J., Rosenstiel, T. N., Monson, R. K., and Fall R.: Transient Releases of Acetaldehyde From Tree Leaves - Products of a Pyruvate Overflow Mechanism?, Plant Cell Environ., 25, 1121-1131, doi:10.1046/j.0016-8025.2002.00889.x, 2002.

Karl, T., Guenther, A., Spirig, C., Hansel, A., and Fall, R.: Seasonal Variation of Biogenic VOC Emissions Above a Mixed Hardwood Forest in Northern Michigan. Geophys. Res. Letts., 30, 2186, doi:10.1029/2003GL018432, 2003.

Karl, T., Harley, P., Guenther, A., Rasmussen, R., Baker, B., Jardine, K., and Nemitz, E.: The bi-directional exchange of oxygenated VOCs between a loblolly pine (Pinus taeda) planta- 
tion and the atmosphere, Atmos. Chem. Phys., 5, 3015-3031, doi:10.5194/acp-5-3015-2005, 2005.

Karl, T., Harley, P., Emmons, L., Thornton, B., Guenther, A., Basu, C., Turnipseed, A., and Jardine, K.: Efficient Atmospheric Cleansing of Oxidized Organic Trace Gases by Vegetation, Science, 330, 816-819, doi:10.1126/science.1192534, 2010.

Kesselmeier, J.: Exchange of short-chain oxygenated volatile organic compounds (VOCs) between plants and the atmosphere: A compilation of field and laboratory studies, J. Atmos. Chem., 29, 219-233, 2001.

Kesselmeier, J., Bode, K., Hoffman, U., Muller, H., Schaffer, L., Wolf, A., Ciccioli, P., Brancaleoni, E., Cecinato, A., Frattoni, M., Foster, P., Ferrari, C., Jacob, V., Fugit, J. L., Dutaur, L., Simon, V., and Torres, L.: Emission of short chained organic acids, aldehydes, monoterpenes from Quercus Ilex L. and Pinus pinea L. in relation to physiological activities, carbon budget and emission algorithms, Atmos. Environ., 31, 119-133, 1997.

Kreuzwieser, J., Kühnemann, F., Martis, A., Rennenberg, H., and Urban, W.: Diurnal Pattern of Acetaldehyde Emission by Flooded Poplar Trees, Physiol. Plant., 108, 79-86, doi:10.1034/j.1399-3054.2000.108001079.x, 2000.

Lee, B. H., Munger, J. W., Wofsy, S. C., and Goldstein, A. H.: Anthropogenic emissions of non-methane hydrocarbons in the north-eastern United States: Measured seasonal variations from 1992-1996 and 1999-2001, J. Geophys. Res., 111, D20307, doi:10.1029/2005JD006172, 2006.

McKinney, K. A., Lee, B. H., Vasta, A., Pho, T. V., and Munger, J. W.: Emissions of isoprenoids and oxygenated biogenic volatile organic compounds from a New England mixed forest, Atmos. Chem. Phys., 11, 4807-4831, doi:10.5194/acp-11-4807-2011, 2011.

Millet, D. B., Guenther, A., Siegel, D. A., Nelson, N. B., Singh, H. B., de Gouw, J. A., Warneke, C., Williams, J., Eerdekens, G., Sinha, V., Karl, T., Flocke, F., Apel, E., Riemer, D. D., Palmer, P. I., and Barkley, M.: Global atmospheric budget of acetaldehyde: 3-D model analysis and constraints from in-situ and satellite observations, Atmos. Chem. Phys., 10, 3405-3425, doi:10.5194/acp-10-3405-2010, 2010.

Müller, M., Graus, M., Ruuskanen, T. M., Schnitzhofer, R., Bamberger, I., Kaser, L., Titzmann, T., Hörtnagl, L., Wohlfahrt, G., Karl, T., and Hansel, A.: First eddy covariance flux measurements by PTR-TOF, Atmos. Meas. Tech., 3, 387-395, doi:10.5194/amt-3-387-2010, 2010.

Munger W. and Wofsy S.: Canopy-Atmosphere Exchange of Carbon, Water and Energy at Harvard Forest EMS Tower since 1991, Harvard Forest Data Archive: HF004, available at: http://harvardforest.fas.harvard.edu:8080/exist/apps/datasets/ showData.html?id=hf004 (last access: 10 December 2016), 1999a.

Munger W. and Wofsy S.: Concentrations and Surface Exchange of Air Pollutants at Harvard Forest EMS Tower since 1990, Harvard Forest Data Archive: HF066, available at: http://harvardforest.fas.harvard.edu:8080/exist/apps/datasets/ showData.html?id=hf066 (last access: 10 December 2016), 1999b.

Munger W. and Wofsy S.: Biomass Inventories at Harvard Forest EMS Tower since 1993, Harvard Forest Data Archive: HF069, available at: http://harvardforest.fas.harvard.edu:8080/
exist/apps/datasets/showData.html?id=hf069 (last access: 10 December 2016), 1999c.

Munger, J. W., Wofsy, S. C., Bakwin, P. S., Fan, S.-M., Goulden, M. L., Daube, B. C., Goldstein, A. H., Moore, K. E., and Fitzjarrald, D. R.: Atmospheric Deposition of Reactive Nitrogen Oxides and Ozone in a Temperate Deciduous Forest and a Subarctic Woodland: 1. Measurements and Mechanisms, J. Geophys. Res., 101, 12639-12657, doi:10.1029/96JD00230, 1996.

Munger, J. W., Fan, S. M. Bakwin, P. S., Goulden, M. L., Goldstein, A. H., Colman, A. S., and Wofsy, S. C.: Regional budgets for nitrogen oxides from continental sources: Variations of rates for oxidation and deposition with season and distance from source regions, J. Geophys. Res., 103, 8355-8368, doi:10.1029/98JD00168, 1998.

Nemecek-Marshall, M., MacDonald, R. C., Franzen, J. J., Wojciechowski, C. L., and Fall, R.: Methanol Emission From Leaves: Enzymatic Detection of Gas-Phase Methanol and Relation of Methanol Fluxes to Stomatal Conductance and Leaf Development, Plant Physiol., 108, 1359-1368, 1995.

Niinemets, Ü. and Reichstein, M.: Controls on the Emission of Plant Volatiles Through Stomata: a Sensitivity Analysis, J. Geophys. Res., 108, 4211, doi:10.1029/2002JD002626, 2003a.

Niinemets, Ü. and Reichstein, M.: Controls on the Emission of Plant Volatiles Through Stomata: Differential Sensitivity of Emission Rates to Stomatal Closure Explained, J. Geophys. Res., 108, 4208, doi:10.1029/2002JD002620, 2003b.

Niinemets, Ü, Loreto, F., and Reichstein, M.: Physiological and Physicochemical Controls on Foliar Volatile Organic Compound Emissions, Trends Plant Sci., 9, 180-186, doi:10.1016/j.tplants.2004.02.006, 2004.

O'Connor, F. M., Johnson, C. E., Morgenstern, O., Abraham, N. L., Braesicke, P., Dalvi, M., Folberth, G. A., Sanderson, M. G., Telford, P. J., Voulgarakis, A., Young, P. J., Zeng, G., Collins, W. J., and Pyle, J. A.: Evaluation of the new UKCA climatecomposition model - Part 2: The Troposphere, Geosci. Model Dev., 7, 41-91, doi:10.5194/gmd-7-41-2014, 2014.

Park, J. H., Goldstein, A. H., Timkovsky, J., Fares, S., Weber, R., Karlik, J., and Holzinger, R.: Active Atmosphere-Ecosystem Exchange of the Vast Majority of Detected Volatile Organic Compounds, Science, 341, 643-647, doi:10.1126/science.1235053, 2013.

Parker, G. G.: Light Transmittance in a Northeastern Mixed Hardwood Canopy, Smithsonian Environmental Research Center Technical Report, 1998.

Sander, R.: Compilation of Henry's Law Constants for Inorganic and Organic Species of Potential Importance in Environmental Chemistry, 1999, available at: http://www.henrys-law.org/ henry-3.0.pdf (last access: 10 December 2016), 1999.

Seco, R., Peñuelas, J., and Filella, I.: Short-Chain Oxygenated VOCs: Emission and Uptake by Plants and Atmospheric Sources, Sinks, and Concentrations, Atmos. Environ., 41, 2477 2499, doi:10.1016/j.atmosenv.2006.11.029, 2007.

Seco, R., Karl, T., Guenther, A., Hosman, K. P., Pallardy, S. G., Gu, L., Geron, C., Harley, P., and Kim, S.: EcosystemScale Volatile Organic Compound Fluxes During an Extreme Drought in a Broadleaf Temperate Forest of the Missouri Ozarks (Central USA), Glob. Change Biol., 21, 3657-3674, doi:10.1111/gcb.12980, 2015. 
Shuttleworth, W. J., Gash, J. H. C., Lloyd, C. R., Moore, C. J., Roberts, J., Marques, A. D., Fisch, G., Silva, V. D., Ribeiro, M. D. G., Molion, L. C. B., Sa, L. D. D., Nobre, J. C. A., Cabral, O. M. R., Patel, S. R., and Demoraes, J. C.: Eddy-Correlation Measurements of Energy Partition for Amazonian Forest, Q. J. Roy. Meteorol. Soc., 110, 1143-1162, doi:10.1002/qj.49711046622, 1984.

Singh, H. B., Kanakidou, M., Crutzen, P. J., and Jacob, D. J.: High Concentrations and Photochemical Fate of Oxygenated Hydrocarbons in the Global Troposphere, Nature, 378, 50-54, doi:10.1038/378050a0, 1995.

Stavrakou, T., Guenther, A., Razavi, A., Clarisse, L., Clerbaux, C., Coheur, P.-F., Hurtmans, D., Karagulian, F., De Mazière, M., Vigouroux, C., Amelynck, C., Schoon, N., Laffineur, Q., Heinesch, B., Aubinet, M., Rinsland, C., and Müller, J.-F.: First space-based derivation of the global atmospheric methanol emission fluxes, Atmos. Chem. Phys., 11, 4873-4898, doi:10.5194/acp-11-4873-2011, 2011.

Steiner, A. L., Pressley, S. N., Botros, A., Jones, E., Chung, S. H., and Edburg, S. L.: Analysis of coherent structures and atmosphere-canopy coupling strength during the CABINEX field campaign, Atmos. Chem. Phys., 11, 11921-11936, doi:10.5194/acp-11-11921-2011, 2011.

Stroud, C., Makar, P., Karl, T., Guenther, A., Geron, C., Turnipseed, A., Nemitz, E., Baker, B., Potosnak, M., and Fuentes, J. D.: Role of canopy-scale photochemistry in modifying biogenic atmosphere exchange of reactive terpene species: Results from the CELTIC field study, J. Geophys. Res., 110, D17303, doi:10.1029/2005JD005775, 2005.
Tie, X., Guenther, A., and Holland, E.: Biogenic Methanol and Its Impacts on Tropospheric Oxidants, Geophys. Res. Lett., 30, 1881, doi:10.1029/2003GL017167, 2003.

Urbanski, S., Barford, C., Wofsy, S., Kucharik, C., Pyle, E., Budney, J., McKain, K., Fitzjarrald, D., Czikowsky, M., and Munger, J. W.: Factors controlling $\mathrm{CO}_{2}$ exchange on timescales from hourly to decadal at Harvard Forest, J. Geophys. Res., 112, G02020, doi:10.1029/2006JG000293, 2007.

Wesely, M. L.: Parameterization of Surface Resistances to Gaseous Dry Deposition in Regional-Scale Numerical-Models, Atmos. Environ., 23, 1293-1304, doi:10.1016/0004-6981(89)90153-4, 1989.

Wild, O., Prather, M. J., Akimoto, H., Sundet, J. K., Isaksen, I. S. A., Crawford, J. H., Davis, D. D., Avery, M. A., Kondo, Y., Sachse, G. W., and Sandholm, S. T.: Chemical transport model ozone simulations for spring 2001 over the western Pacific: Regional ozone production and its global impacts, J. Geophys. Res., 109, D15S02, doi:10.1029/2003JD004041, 2004.

Wohlfahrt, G., Amelynck, C., Ammann, C., Arneth, A., Bamberger, I., Goldstein, A. H., Gu, L., Guenther, A., Hansel, A., Heinesch, B., Holst, T., Hörtnagl, L., Karl, T., Laffineur, Q., Neftel, A., McKinney, K., Munger, J. W., Pallardy, S. G., Schade, G. W., Seco, R., and Schoon, N.: An ecosystem-scale perspective of the net land methanol flux: synthesis of micrometeorological flux measurements, Atmos. Chem. Phys., 15, 7413-7427, doi:10.5194/acp-15-7413-2015, 2015. 